\title{
Genomic analysis of the secretion stress response in the enzyme-producing cell factory Aspergillus niger Thomas Guillemette ${ }^{1,6}$, Noël NME van Peij ${ }^{2}$, Theo Goosen ${ }^{3}$, Karin Lanthaler ${ }^{4}$, Geoffrey D Robson ${ }^{4}$, Cees AMJJ van den Hondel ${ }^{5}$, Hein Stam² and David B Archer*1
}

Address: ${ }^{1}$ School of Biology, University of Nottingham, University Park, Nottingham, NG7 2RD, UK, ${ }^{2}$ DSM Food Specialties, P.O. Box 1, 2600 MA Delft, The Netherlands, ${ }^{3}$ Biocentre, HAN University, Laan van Scheut 2, 6525 EM Nijmegen, The Netherlands, ${ }^{4}$ Faculty of Life Sciences, Stopford Building, University of Manchester, Oxford Road, Manchester M13 9PT, UK, ${ }^{5}$ Clusius Laboratory, Leiden University, P.O. Box 9505,2300 RA Leiden, The Netherlands and 'Laboratoire de Microbiologie, UMR 77 Pathologie Végétale, Université d'Angers, 2 bd Lavoisier, 49045 Angers cedex, France

Email: Thomas Guillemette - thomas.guillemette@univ-angers.fr; Noël NME van Peij - Noel.Peij-van@DSM.COM;

Theo Goosen - t.goosen@chello.nl; Karin Lanthaler - karin.lanthaler@man.ac.uk; Geoffrey D Robson - geoff.robson@man.ac.uk; Cees AMJ van den Hondel - Hondel@rulbim.leidenuniv.nl; Hein Stam - Hein.Stam@DSM.COM; David B Archer* - david.archer@nottingham.ac.uk

* Corresponding author

Published: II June 2007

BMC Genomics 2007, 8:158 doi:10.1186/147|-2164-8-158
Received: 16 January 2007

Accepted: II June 2007

This article is available from: http://www.biomedcentral.com/I47I-2/64/8/I58

(C) 2007 Guillemette et al; licensee BioMed Central Ltd.

This is an Open Access article distributed under the terms of the Creative Commons Attribution License (http://creativecommons.org/licenses/by/2.0), which permits unrestricted use, distribution, and reproduction in any medium, provided the original work is properly cited.

\begin{abstract}
Background: Filamentous fungi such as Aspergillus niger have a high capacity secretory system and are therefore widely exploited for the industrial production of native and heterologous proteins. However, in most cases the yields of non-fungal proteins are significantly lower than those obtained for fungal proteins. One well-studied bottleneck appears to be the result of mis-folding of heterologous proteins in the ER during early stages of secretion, with related stress responses in the host, including the unfolded protein response (UPR). This study aims at uncovering transcriptional and translational responses occurring in A. niger exposed to secretion stress.
\end{abstract}

Results: A genome-wide transcriptional analysis of protein secretion-related stress responses was determined using Affymetrix DNA GeneChips and independent verification for selected genes. Endoplasmic reticulum (ER)associated stress was induced either by chemical treatment of the wild-type cells with dithiothreitol (DTT) or tunicamycin, or by expressing a human protein, tissue plasminogen activator (t-PA). All of these treatments triggered the UPR, as shown by the expression levels of several well-known UPR target genes. The predicted proteins encoded by most of the up-regulated genes function as part of the secretory system including chaperones, foldases, glycosylation enzymes, vesicle transport proteins, and ER-associated degradation proteins. Several genes were down-regulated under stress conditions and these included several genes that encode secreted enzymes. Moreover, translational regulation under ER stress was investigated by polysomal fractionation. This analysis confirmed the post-transcriptional control of hacA expression and highlighted that differential translation also occurs during ER stress, in particular for some genes encoding secreted proteins or proteins involved in ribosomal biogenesis and assembly.

Conclusion: This is first genome-wide analysis of both transcriptional and translational events following protein secretion stress. Insight has been gained into the molecular basis of protein secretion and secretion-related stress in an effective protein-secreting fungus, and provides an opportunity to identify target genes for manipulation in strain improvement strategies. 


\section{Background}

Many species of filamentous fungi such as Aspergillus niger are effective secretors of, mainly, hydrolytic enzymes to facilitate their saprophytic lifestyles by providing substrates from polymeric organic materials. This high capacity secretory system has driven the exploitation of filamentous fungi as cell factories for provision of enzymes used in a wide variety of applications [1]. Since the availability of gene-transfer systems, several fungal species have become potentially excellent hosts for achieving commercial yields of heterologous proteins. However, the yields of recombinants enzymes are often lower than desired, and this is especially so when the donor organism is not a fungus [2]. Many approaches have been used to overcome the bottlenecks to achieving high-secreted yields of heterologous proteins from fungi $[2,3]$ but the levels do not reach the same level as the best native protein.

Several data suggest that bottlenecks mainly exist at the post-transcriptional level, and most probably within the secretory pathway $[4,5]$. The ER orchestrates the folding and some post-translational modifications of proteins that reside in, or pass through, the endomembrane system of a eukaryotic cell. In expression systems, the large flux of proteins being translocated into the ER generates a need to enhance the efficiency of protein folding and transport as well as the quality control of the synthesized proteins. Increased flux of proteins through the ER, especially those which do not fold correctly, or at least with the required kinetics, lead to the induction of stress responses that are collectively called protein secretion stress or ER stress. Mechanisms that allow the cell to sense the state of the lumen and to respond to ER stress conditions have been characterized in detail in the yeast Saccharomyces cerevisiae and in mammalian cells [6]. The first of these mechanisms is the unfolded protein response (UPR), a complex intracellular signaling pathway that increases the transcriptional activity of a number of genes involved in protein folding, glycosylation and transport $[6,7]$. The UPR also appears to be intimately linked to the ER-associated (protein) degradation (ERAD) pathway $[7,8]$, in which misfolded proteins in the ER lumen are retrotranslocated (dislocated) through the translocon to the cytoplasm, and are ubiquitinated and degraded by the proteasome [9]. Recently, a novel type of feed-back mechanism, termed repression under secretion stress (RESS), has been suggested in filamentous fungi $[10,11]$. It functions during secretion stress and down-regulates the transcript levels of some genes. A gene array study under ER stress conditions has recently been published with $A$. nidulans where ca. $30 \%$ of the predicted genes were represented on the array [12]. They described the first attempt to analyze in part the influence of the production and secretion of a heterologous protein on the cellular transcript profile of a filamen- tous fungus. A complete analysis of ER stress responses in the yeast $S$. cerevisiae, a fungus that does not secrete proteins as effectively as A. niger has also been described [7].

The ER surveillance system continuously coordinates the activity and participation of the processing and degradation pathways for unfolded proteins. Upon accumulation of unfolded proteins in the ER lumen, the UPR is activated, reducing the amount of new protein translocated into the ER lumen, increasing dislocation of proteins from the lumen of the ER and, then, their degradation, and bolstering the protein-folding capacity of the ER. Thus, understanding the process of folding and the stress responses in filamentous fungi may hold the major key to improving their use as cell factories for production of recombinant proteins. A genome-wide expression analysis of these secretion-related stress responses has never been reported in industrially-exploited species, since genome sequence data has not previously been available. Recently, the sequencing and annotation of the genome of A. niger have been completed [13]. DNA GeneChips have been made available and provide an unprecedented resource for exploring expression profiles in response to particular environmental cues. Here, we report the first gene expression analysis studies showing the response to various secretion stresses and assessing the breadth of the UPR in A. niger.

\section{Results}

\section{Transcriptional analysis of the ER stress response}

To gain further insight into the UPR of filamentous fungi, we identified transcriptional targets of this signaling pathway in A. niger by monitoring mRNA levels using oligonucleotide arrays on Affymetrix GeneChips. The UPR was induced by treating mycelium cultures for $2 \mathrm{~h}$ with two chemical agents which disrupt protein folding in the ER. Dithiothreitol (DTT) is a strong reducing agent that prevents disulfide bond formation. Tunicamycin is a drug that inhibits $\mathrm{N}$-linked glycosylation by preventing core oligosaccharide addition to nascent polypeptides and thereby blocks protein folding and transit through the ER [14]. Finally, a strain [15] producing recombinant tissue plasminogen activator (t-PA), a serine protease, was chosen to assess the UPR under conditions of heterologous protein production. Previous studies indicated that the expression of t-PA in A. niger leads to the appearance of the spliced form of hacA mRNA (hacA ${ }^{i}$ ) (which is translated to yield the UPR-mediating transcription factor HacA) and the simultaneous up-regulation of bipA and pdiA $[15,16]$. Unlike with $S$. cerevisiae [7] it was not possible to include strains of $A$. niger that are devoid of genes encoding key mediators of the UPR such as ireA and hacA because such strains are not available despite the cloning and functional characterization of those genes $[7,17]$. Deletion of ireA in A. niger has not been achieved and the 
only $\Delta$ hacA strain described to date grows very differently from the wild-type strain of $A$. niger (H. Mulder, personal communication) and, anyway, is not generally available.

Replicate experiments were performed for each of the three stress responses. All (experimental and control) chips were normalized/ scaled to a target intensity of 100 by global scaling (details regarding Scaling and Normalization are listed in the Affymetrix Microarray Suite User Guide Version 5.0, Appendix D) with scaling factors being comparable for all comparisons [see Additional file 1]. Next, intraexperiment and inter-experiment GeneChip comparisons were processed for each of the 3 stress conditions and all genes with a detected transcript in at least one condition were checked for even distribution of intensities. For all the probe sets on the Affymetrix GeneChip, we determined the fold change in expression due to each treatment by comparing its expression level in the treated sample to its level in the untreated control. Two comparisons were processed for each of the 3 stress conditions. Increased expression of bipA, pdiA (two genes expected to be up-regulated by ER stress) and an uncharacterised $A$. niger gene (An02g13410, putative homolog of an acetyl CoA transporter) shown on the GeneChips to be up-regulated, was confirmed in response to both chemical treatments and to t-PA production by Northern hybridisation (Fig. 1A). Increased levels of hacA ${ }^{i}$ mRNA was also confirmed by RT-PCR across the hacA mRNA intron, and RT-PCR was also used to confirm both the GeneChip and Northern hybridisation data showing that the mRNA levels of bipA and pdiA were increased under stress (Fig. 1B). For tunicamycin treatment especially but also t-PA expression, overall variations in gene expression levels were generally small, whereas DTT treatment showed a relatively large reponse [see Additional files 2, 3, 4]. With standard criteria of a fold change of 2, less than 10 differentially-expressed genes would be detected in the tunicamycin treatment and therefore selection criteria were adjusted to a less stringent 1.5 -fold change for all treatments. According to the analytical criteria adopted (at least 1.5 -fold change), a list of induced genes was produced with 79 independent entries for the heterologous protein production condition, 38 entries for the tunicamycin treatment and 865 entries for the DTT treatment. The repressed gene sets identified with these restrictions constituted 110, 11 and 774 independent entries from the t-PA producing strain and for the tunicamycin and DTT treatments respectively. Tables 1 and 2 present the lists of genes that were upregulated or down-regulated by at least 2 of the 3 treatments respectively. A more complete list of genes differentially expressed following each treatment (tunicamycin and t-PA production) is provided in the supplementary information [see Additional files 5 and 6]. Moreover, an additional GeneChip experiment was conducted after a $1 \mathrm{~h}$ exposure to tunicamycin and results are also included in those Tables.

\section{Comparisons of ER stress induced under different conditions}

Comparison of the signal intensities on the GeneChips showed that, while the replicates for each stress condition clustered closely together, the DTT stress was more distant from the t-PA and tunicamycin stresses which were more

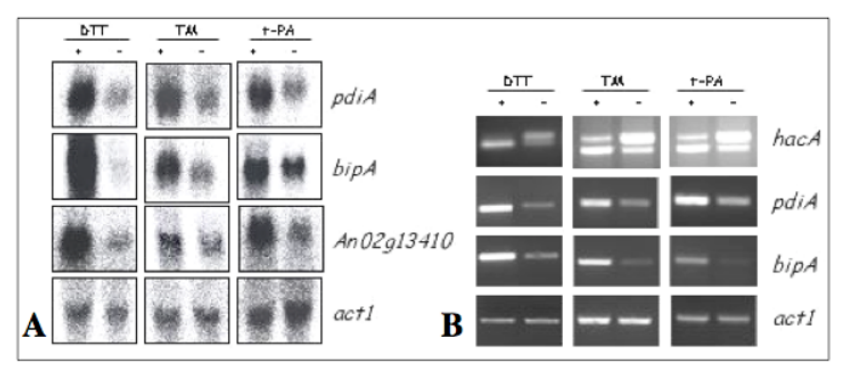

\section{Figure I}

GeneChip results were confirmed for some genes using Northern blotting and RT-PCR. Examples are provided for both Northern blots (A) and RT-PCR (B). Note that the RT$P C R$ for the hacA mRNA was designed to indicate enhanced splicing of the hacA mRNA intron under stress conditions (DTT, tunicamycin and production of t-PA). This is shown as a relative increase in the amount of the processed (lower band) hacA form of the mRNA compared to the unprocessed higher band (hacAu). Probing or PCR for an actin gene was used as a non-stress-responsive control transcript.

closely clustered together (Fig. 2). The numbers of genes that were induced or repressed under each of the conditions, together with a summary of those regulated in more than one condition, are shown in Fig. 3. Of the up-regulated genes, only ten were found in all three conditions and these are indicated in Table 1. This list is dominated by genes that are expected to be directly influenced by the UPR, e.g. $p d i A, p r p A, b i p A, c l x A$, and $l h s A$. It is striking that the majority of the DTT-induced genes were not anticipated ER stress genes and we conclude that, although DTT can induce the expression of a large number of genes it is not the most appropriate stress agent for studies of ER stress, a conclusion reached independently elsewhere $[12,18]$. In contrast, most of the tunicamycin-induced genes are also induced by t-PA and/or DTT and about half of the t-PA-induced genes are also induced by either DTT or tunicamycin. As previously reported in yeast [7], our results show that ER stress responses affect multiple ER and secretory pathway functions. As expected, we observe induction of ER-resident chaperones and other proteins involved in protein folding. However, these represent only a fraction of this set of target genes and we also found several categories of induced genes with other functions throughout the secretory pathway including translocation, protein glycosylation, vesicular transport, ER-associated degradation and lipid metabolism.

Fewer genes were down-regulated overall than were upregulated and there were no genes down-regulated in all conditions. Exposure to tunicamycin for $2 \mathrm{~h}$ caused downregulation of only eleven genes in total compared to 38 up-regulated. Over one hundred genes (t-PA) and nearly 800 genes (DTT treatment) were down-regulated (Table 
Table I: Genes induced by at least 2 treatments.

\begin{tabular}{|c|c|c|c|c|c|}
\hline \multirow{2}{*}{$\sum_{\infty}^{\infty} \quad \frac{\text { DSM code }}{\text { Protein Folding }}$} & \multicolumn{5}{|l|}{ Predicted protein } \\
\hline & & Tun I h & Tun 2 h & DTT & tPA \\
\hline An0lgI3220 & similar to the chaperone LHSI & $3.4 \pm 0.5$ & $1.5 \pm 0.7$ & $2.5 \pm 0.3$ & $1.7 \pm 0.8$ \\
\hline An02gl 4800 & Protein disulfide isomerase PDIA & $1.7 \pm 0.1$ & $2.6 \pm 0.1$ & $2.2 \pm 0.004$ & $1.9 \pm 0.01$ \\
\hline Anolg04600 & Protein disulfide isomerase PRPA & $3.8 \pm 0.2$ & $2.6 \pm 0.3$ & $4.0 \pm 0.3$ & $2.2 \pm 0.2$ \\
\hline An0 Ig08420 & calnexin CNXA & $3.0 \pm 0.3$ & $2.3 \pm 0.1$ & $3.2 \pm 0.5$ & $2.2 \pm 0.1$ \\
\hline An I Ig04 I 80 & chaperone BIPA & $3.2 \pm 0.7$ & $2.6 \pm 0.6$ & $4.7 \pm 0.6$ & $2.4 \pm 0.008$ \\
\hline An I6g07620 & similar to ER oxidising protein EROI & $1.9 \pm 0.7$ & $2.6 \pm 0.4$ & $3.1 \pm 0.9$ & $3.1 \pm 0.5$ \\
\hline An I8g02020 & Protein disulfide isomerase TIGA & $* 1.3 \pm 0.5$ & $\mathrm{I} .7 \pm 0.4$ & $* 1.7 \pm 0.03$ & $1.8 \pm 0.02$ \\
\hline AnIIgII250 & similar to the chaperone P58IPK Homo sapiens & $2.5 \pm 0.6$ & $1.9 \pm 0.07$ & $* 1.3 \pm 0.3$ & $1.5 \pm 0.05$ \\
\hline An05g00880 & similar to dnaJ protein homolog SCJI & $2.5 \pm 0.3$ & $1.5 \pm 0.06$ & $2.1 \pm 0.3$ & $* 1.6 \pm 0.2$ \\
\hline \multicolumn{6}{|c|}{ Translocation/signal peptidase complex } \\
\hline An0 $\lg \mid 3070$ & similar to ER protein-translocation complex subunit SEC63 & $* 1.3 \pm 0.5$ & $1.6 \pm 0.09$ & $* 1.7 \pm 0.2$ & $2.5 \pm 0.1$ \\
\hline An I6g08830 & similar to component of subcomplex SEC7I & $1.8 \pm 0.2$ & $* 1.4 \pm 0.08$ & $1.9 \pm 0.4$ & $* 1.7 \pm 0.04$ \\
\hline An 17g00090 & similar to translocation complex subunit SEC72 & $1.7 \pm 0.2$ & $1.6 \pm 0.2$ & $2.1 \pm 0.5$ & $* 1.3 \pm 0.1$ \\
\hline An0lgII630 & similar to translocation complex component SSSI & $2.5 \pm 0.2$ & $1.6 \pm 0.3$ & $1.6 \pm 0.04$ & $* 1.6 \pm 0.1$ \\
\hline An09g05420 & similar to signal peptidase subunit SPC3 & $2.7 \pm 0.3$ & $1.8 \pm 0.2$ & $1.5 \pm 0.2$ & $1.8 \pm 0.8$ \\
\hline An0lg00560 & similar to signal peptidase subunit SECII & $2.2 \pm 0.4$ & $1.9 \pm 0.06$ & $* 1.1 \pm 0.2$ & $1.7 \pm 0.009$ \\
\hline AnI5g06470 & similar to signal sequence receptor $\alpha$-subunit & $1.8 \pm 0.6$ & $1.5 \pm 0.07$ & $* 1.5 \pm 0.4$ & $1.5 \pm 0.08$ \\
\hline \multicolumn{6}{|l|}{ Glycosylation } \\
\hline An $14 g 05910$ & similar to mannosyltransferase ALG2 & $2.3 \pm 0.5$ & $* 2.9 \pm 1.1$ & $* 1.7 \pm 0.2$ & $1.5 \pm 0.1$ \\
\hline An I8g02360 & similar to mannosyltransferase ALG3 & $2.4 \pm 0.4$ & $4.8 \pm 2.1$ & $*_{-1} .4 \pm 0.3$ & $2.0 \pm 0.3$ \\
\hline An03g04410 & similar to glucosyltransferase ALG5 & $1.8 \pm 0.3$ & $* 1.7 \pm 0.001$ & $2.2 \pm 0.4$ & $1.7 \pm 0.1$ \\
\hline $\mathrm{An} 02 \mathrm{~g} 03240$ & similar to $\mathrm{N}$-acetylglucosaminephosphotransferase ALG7 & $1.8 \pm 0.3$ & $2.8 \pm 0.5$ & $2.1 \pm 0.1$ & $* 1.7 \pm 0.2$ \\
\hline An07g04190 & similar to glycosyltransferase WBPI & $1.9 \pm 0.2$ & $1.8 \pm 0.09$ & $* 1.4 \pm 0.2$ & $1.7 \pm 0.09$ \\
\hline An02gl 4560 & oligosaccharyltransferase alpha subunit OSTA & $1.7 \pm 0.09$ & $1.6 \pm 0.06$ & $*_{-1} .4 \pm 0.007$ & $1.6 \pm 0.4$ \\
\hline Anl8g03920 & similar to oligosaccharyltransferase subunit OST2 & $1.9 \pm 0.4$ & $1.5 \pm 0.2$ & $1.5 \pm 0.1$ & $* 1.2 \pm 0.2$ \\
\hline An I 8g04260 & similar to UDP-galactose transporter HUTI & $2.3 \pm 0.2$ & $*_{-1} .0 \pm 0.5$ & $2.1 \pm 0.3$ & $1.9 \pm 0.2$ \\
\hline Anl8g06220 & similar to alpha-mannosidase MNSI & $* 1.1 \pm 0.5$ & $2.4 \pm 0.6$ & $* 1.2 \pm 0.004$ & $1.8 \pm 0.1$ \\
\hline An $13 g 00620$ & similar to beta subunit of an ER alpha-glucosidase & $* 1.4 \pm 0.5$ & $1.9 \pm 0.2$ & $*_{-1.8 \pm 0.1}$ & $1.7 \pm 0.2$ \\
\hline An $15 g 01420$ & similar to glucosidase I CWH4I & $* 1.3 \pm 0.5$ & $1.7 \pm 0.5$ & $*_{-1} .8 \pm 0.2$ & $1.6 \pm 0.01$ \\
\hline An04g05250 & similar to dolichol synthesis protein RER2 & $1.7 \pm 0.1$ & $* 1.3 \pm 0.08$ & $2.2 \pm 0.1$ & $* 1.2 \pm 0.1$ \\
\hline An02gl4940 & similar to flippase RFTI & $* 1.5 \pm 0.5$ & $*_{-1} .0 \pm 0.9$ & $1.7 \pm 0.1$ & $1.7 \pm 0.1$ \\
\hline \multicolumn{6}{|c|}{ Vesicle trafficking/transport } \\
\hline An03g04940 & similar to COPII vesicle coat component protein ERV4I & $2.2 \pm 0.07$ & $1.9 \pm 0.08$ & $2.4 \pm 0.8$ & $2.3 \pm 0.6$ \\
\hline An0lg04320 & similar to COPII vesicle coat component protein ERV46 & $2.1 \pm 0.2$ & $2.4 \pm 0.3$ & $* 1.5 \pm 0.1$ & $2.1 \pm 0.05$ \\
\hline An02g04250 & similar to ER protein P58 (lectin family) Rattus norvegicus & $1.7 \pm 0.5$ & $1.8 \pm 0.2$ & $* 1.2 \pm 0.01$ & $1.5 \pm 0.3$ \\
\hline An02g08450 & secretory gene product NSFA & $1.5 \pm 0.2$ & $* 1.2 \pm 0.006$ & $2.5 \pm 0.06$ & $* 1.1 \pm 0.06$ \\
\hline An08g06780 & similar to ER to Golgi transport protein USOI & $2.0 \pm 0.1$ & $* 6.5 \pm 3.2$ & $5.3 \pm 3.6$ & $* 1.7 \pm 0.6$ \\
\hline \multicolumn{6}{|c|}{ Proteolytic degradation } \\
\hline An 16g06750 & similar to D-stereospecific aminopeptidase & $* 2.0 \pm 0.5$ & $2.1 \pm 0.1$ & $14.0 \pm 8.0$ & $* 2.1 \pm 0.2$ \\
\hline An08g09000 & similar to ubiquitin like protein DSK2 & $1.7 \pm 0.4$ & $* 1.0 \pm 0.1$ & $3.0 \pm 0.2$ & $*_{-1.1} \pm 0.2$ \\
\hline An09g00950 & similar to aminopeptidase DAP Ochrobactrum anthropi & $1.6 \pm 0.2$ & $*_{-1.7} \pm 0.3$ & $6.2 \pm 1.4$ & $* 1.1 \pm 0.2$ \\
\hline
\end{tabular}


Table I: Genes induced by at least 2 treatments. (Continued)

\begin{tabular}{|c|c|c|c|c|c|}
\hline An02gI34I0 & similar to acetyl-coenzyme $A$ transporter AT-I & $2.4 \pm 0.04$ & $1.8 \pm 0.1$ & $5.4 \pm 0.3$ & $2.3 \pm 0.2$ \\
\hline AnI lg02990 & similar to cytochrome P450 DIT2 & $*_{-1} .2 \pm 0.5$ & $* 1.2 \pm 0.002$ & $2.0 \pm 0.3$ & $1.6 \pm 0.03$ \\
\hline An I 4g07030 & similar to carboxylesterase Aspergillus fumigatus & $* 1.6 \pm 0.5$ & $*-1.9 \pm 1.2$ & $43.0 \pm 5.3$ & $1.7 \pm 0.2$ \\
\hline \multicolumn{6}{|c|}{ Cellular transport } \\
\hline An $12 g 03150$ & similar to multidrug resistance protein ATRD & $2.0 \pm 0.4$ & $*_{-1.1} \pm 0.3$ & $10.1 \pm 2.5$ & $*-1.1 \pm 0.1$ \\
\hline \multicolumn{6}{|l|}{ Translation } \\
\hline An 14g06610 & similar to elongation factor Eefl alpha-A chain TEF2 & $1.6 \pm 0.1$ & $* 1.6 \pm 0.3$ & $8.6 \pm 1.3$ & $* 1.4 \pm 0.3$ \\
\hline \multicolumn{6}{|l|}{ Stress related } \\
\hline An $12 g 03580$ & similar to glutathione $\mathrm{S}$-transferase $3 \mathrm{MGST} 3 \mathrm{H}$. sapiens & $* 1.2 \pm 0.5$ & $* 1.3 \pm 0.1$ & $3.2 \pm 0.5$ & $5.1 \pm 1.4$ \\
\hline AnOlgI4I00 & weakly similar to stress protein HERP Mus musculus & $2.0 \pm 0.1$ & $* 1.5 \pm 0.2$ & $1.5 \pm 0.3$ & $* 1.8 \pm 0.3$ \\
\hline \multicolumn{6}{|c|}{ Cell Cycle and DNA processing } \\
\hline An0Ig08I70 & similar to DNA repair endonuclease RADI S. pombe & $1.8 \pm 0.5$ & $* 1.8 \pm 0.2$ & $2.2 \pm 1.1$ & $* 1.6 \pm 0.2$ \\
\hline \multicolumn{6}{|c|}{ C-compound and carbohydrate metabolism } \\
\hline An09g06400 & similar to chitinase CHIA Aspergillus nidulans & $-2.1 \pm 0.5$ & $* 1.0 \pm 0.008$ & $2.4 \pm 0.3$ & $2.3 \pm 0.8$ \\
\hline An I6g09070 & similar to glucosamine-6-phosphate deaminase $A$. fumigatus & $*_{-1.2} \pm 0.5$ & $* 1.4 \pm 0.2$ & $2.1 \pm 0.08$ & $2.4 \pm 0.7$ \\
\hline \multicolumn{6}{|c|}{ 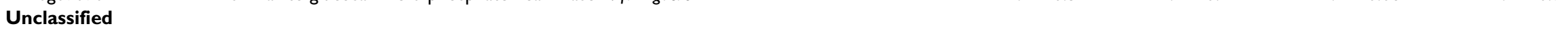 } \\
\hline An08g03960 & hypothetical endoplasmic reticulum associated protein & $2.1 \pm 0.09$ & $1.7 \pm 0.07$ & $3.3 \pm 1.0$ & $1.6 \pm 0.06$ \\
\hline $\mathrm{An} 02 \mathrm{~g} 00120$ & hypothetical protein & $* 2.4 \pm 0.5$ & $* 1.2 \pm 0.3$ & $2.0 \pm 0.5$ & $1.8 \pm 0.07$ \\
\hline An08g03970 & hypothetical protein & $* 1.7 \pm 0.5$ & $2.0 \pm 0.4$ & $* 1.2 \pm 0.02$ & $1.8 \pm 0.1$ \\
\hline An09g00650 & hypothetical protein & $2.0 \pm 0.3$ & $*_{-1.30 .4}$ & $2.7 \pm 0.2$ & $4.0 \pm 1.4$ \\
\hline An $17 g 00660$ & hypothetical protein & $*_{-1.1} \pm 0.2$ & $*_{-1} .5 \pm 0.6$ & $5.0 \pm 2.7$ & $1.6 \pm 0.1$ \\
\hline Anl Ig06970 & hypothetical protein & $* 3.1 \pm 0.3$ & $* 1.7 \pm 0.7$ & $17.3 \pm 6.0$ & $2.3 \pm 0.6$ \\
\hline An 16900070 & hypothetical protein & $*_{-1.4 \pm 0.5}$ & $* 1.1 \pm 0.1$ & $5.1 \pm 0.1$ & $1.5 \pm 0.2$ \\
\hline An 16908470 & hypothetical protein & $* 1.8 \pm 0.3$ & $* 1.1 \pm 0.2$ & $1.5 \pm 0.1$ & $1.5 \pm 0.05$ \\
\hline An02gl4500 & hypothetical protein & $*_{-1} .2 \pm 0.4$ & $* 1.0 \pm 0.1$ & $9.3 \pm 2.7$ & $1.7 \pm 0.1$ \\
\hline An03g00720 & hypothetical protein & $* 1.1 \pm 0.5$ & $*_{-1} .2 \pm 0.06$ & $2.6 \pm 1.1$ & $1.9 \pm 0.7$ \\
\hline An04g02250 & questionable ORF & $* 2.2 \pm 0.3$ & $2.0 \pm 0.2$ & $20.2 \pm 10.3$ & $* 1.3 \pm 0.006$ \\
\hline An $14 g 01990$ & hypothetical protein & $3.0 \pm 0.4$ & $*_{-} .4 \pm 0.2$ & $4.3 \pm 0.9$ & $*_{-1.1} \pm 0.03$ \\
\hline An08g04260 & hypothetical protein & $2.0 \pm 0.6$ & $* 1.7 \pm 0.3$ & $2.4 \pm 0.01$ & $* 1.3 \pm 0.07$ \\
\hline An07g 10280 & hypothetical protein & $2.0 \pm 0.7$ & $* 1.6 \pm 0.08$ & $1.8 \pm 0.9$ & $* 1.6 \pm 0.2$ \\
\hline An09g06130 & hypothetical protein & $2.0 \pm 0.3$ & $* 2 \pm 0.2$ & $1.6 \pm 0.4$ & $* 1.4 \pm 0.09$ \\
\hline An08g09860 & hypothetical protein & $2.3 \pm 0.6$ & $* 1.2 \pm 0.4$ & $7.4 \pm 1.0$ & $*_{-1.4 \pm 0.1}$ \\
\hline An $18 g 06120$ & similar to secreted protein vc33_I & $1.9 \pm 0.2$ & $*_{-} I .1 \pm 0.1$ & $2.2 \pm 0.1$ & $* 1.0 \pm 0.05$ \\
\hline An I 4g06550 & hypothetical protein & $2.1 \pm 0.3$ & $* 1.2 \pm 0.1$ & $2.8 \pm 0.6$ & $* 1.2 \pm 0.1$ \\
\hline An 15g02650 & hypothetical protein & $2.8 \pm 1.5$ & $* 1.1 \pm 0.2$ & $2.8 \pm 0.6$ & $* 1.1 \pm 0.1$ \\
\hline Anl Ig 10800 & similar to probable isochorismatase & $2.3 \pm 0.3$ & $* 1.0 \pm 0.002$ & $11.5 \pm 2.2$ & $* 1.2 \pm 0.2$ \\
\hline An 18901690 & hypothetical protein & $2.3 \pm 1.5$ & $* 2.1 \pm 0.5$ & $2.4 \pm 0.9$ & $* 1.1 \pm 0.1$ \\
\hline An I 6g08680 & hypothetical protein & $1.7 \pm 0.4$ & $*-1.1 \pm 0.2$ & $6.7 \pm 0.5$ & $* 1.1 \pm 0.07$ \\
\hline
\end{tabular}

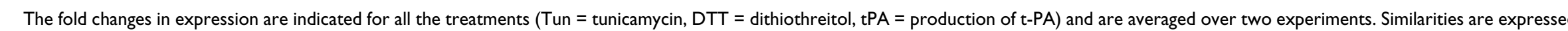
in comparison with the Saccharomyces cerevisiae genome except when indicated. The symbol* indicates that the value does not meet one of the 3 restrictive criteria defined in the Method section. The genes induced by the three treatments are marked in bold. 
Table 2: Genes repressed by at least 2 treatments.

\begin{tabular}{|c|c|c|c|c|c|}
\hline Protein Fate & & Tun I h & Tun 2 h & DTT & tPA \\
\hline \multicolumn{6}{|c|}{ Proteolytic Degradation } \\
\hline An I2g05960 & similar to dipeptidyl peptidase II DPPII Rattus norvegicus & $* 1.3 \pm 0.5$ & $* 1.6 \pm 0.2$ & $-1.9 \pm 0.3$ & $-1.5 \pm 0.6$ \\
\hline An03g01660 & similar to vacuolar aminopeptidase Y APE3 & $-2.1 \pm 0.3$ & $* 1.0 \pm 0.05$ & $-1.7 \pm 0.7$ & $* 1.1 \pm 0.02$ \\
\hline An03g05200 & similar to carboxypeptidase SI Penicillium janthinellum & $-2.1 \pm 0.4$ & $* I .1 \pm 0.4$ & $-1.8 \pm 0.6$ & $*_{-1} .4 \pm 0.08$ \\
\hline An04g0I440 & similar to vacuolar aspartyl protease PEP4 & $-2.1 \pm 0.3$ & $* 1.1 \pm 0.2$ & $-1.6 \pm 0.04$ & $*_{-1} .3 \pm 0.03$ \\
\hline An08g08750 & carboxypeptidase Y CPY & $-1.9 \pm 0.2$ & $* 1.0 \pm 0.06$ & $-2.2 \pm 0.02$ & $*_{-1} .3 \pm 0.04$ \\
\hline An I 4g00620 & similar to aminopeptidase Aspergillus oryzae & $-2.4 \pm 0.5$ & $*_{-1} .0 \pm 0.01$ & $-2.3 \pm 0.1$ & $*_{-1.1} \pm 0.2$ \\
\hline \multicolumn{6}{|c|}{ Lipid metabolism } \\
\hline An I6g01880 & similar to lysophospholipase Aspaergillus foetidus & $*-2.2 \pm 0.5$ & $-1.7 \pm 0.3$ & $-99.8 \pm 5.6$ & $1.4 \pm 0.8$ \\
\hline An02g09540 & similar to choline permease HNMI & $* 1.1 \pm 0.5$ & $* 1.0 \pm 0.6$ & $-2.4 \pm 0.9$ & $-1.9 \pm 0.1$ \\
\hline An 16906090 & similar to choline permease HNMI & $*_{-1.3} \pm 0.3$ & $* 1.1 \pm 0.01$ & $-1.9 \pm 0.2$ & $-2.2 \pm 0.5$ \\
\hline An $15 g 06810$ & similar to cytochrome-b5 reductase MCRI & $* 1.1 \pm 0.2$ & $* 1.6 \pm 0.1$ & $-1.7 \pm 0.3$ & $-2.6 \pm 011$ \\
\hline An0lg03350 & similar to C-8 sterol isomerase ERGI Neurospora crassa & $-1.9 \pm 0.3$ & $* 1.2 \pm 0.2$ & $-2.1 \pm 0.6$ & $*_{-1} .2 \pm 0.3$ \\
\hline$A n 02 g 03580$ & similar to lipid metabolism protein ERG28 & $-1.8 \pm 0.2$ & $* 1.2 \pm 0.02$ & $-2.0 \pm 0.2$ & $*_{-1} .3 \pm 0.06$ \\
\hline An0lg07000 & similar to $\mathrm{C}-14$ sterol reductase ERG24 & $-1.7 \pm 0.1$ & $* 1.2 \pm 0.2$ & $* 3.9 \pm 0.4$ & $-1.9 \pm 0.08$ \\
\hline \multicolumn{6}{|l|}{ Cell wall } \\
\hline An 16g03370 & similar to protein involved in of cell wall biogenesis $\mathrm{CWH} 43$ & $-2.0 \pm 0.2$ & $* 1.2 \pm 0.1$ & $-2.4 \pm 0.1$ & $*_{-1} .2 \pm 0.01$ \\
\hline An l6g07040 & similar to cell wall glucanase SCWIO & $-1.7 \pm 0.1$ & $*_{-1.1} \pm 0.07$ & $-4.0 \pm 0.5$ & $*_{-1} .0 \pm 0.04$ \\
\hline \multicolumn{6}{|c|}{ Amino acid metabolism } \\
\hline An04g00990 & NADP-dependent glutamate dehydrogenase GDHA & $* 1.1 \pm 0.3$ & $*-3.5 \pm 2.0$ & $-3.6 \pm 0.7$ & $-1.5 \pm 0.005$ \\
\hline An 16901610 & similar to hydroxylase BBH Rattus norvegicus & $*_{-1} .2 \pm 0.5$ & $-2.5 \pm 0.7$ & $-13.5 \pm 0.1$ & $*_{-1} .0 \pm 0.5$ \\
\hline An0lg 14730 & similar to lactonizing enzyme I TcMLE Trichosporon cutaneum & $-1.6 \pm 0.1$ & $*_{-1.3 \pm 0.1}$ & $-1.5 \pm 0.2$ & $* 1.3 \pm 0.2$ \\
\hline $\mathrm{An} 02 \mathrm{~g} 00190$ & similar to enantiomer-selective amidase AMDA Rhodococcus sp. & $-2.9 \pm 0.5$ & $* 1.1 \pm 0.2$ & $-2.3 \pm 0.3$ & $*_{-1.3} \pm 0.5$ \\
\hline An $12 g 10000$ & similar to GABA permease GABA Aspergillus nidulans & $*_{-1} .0 \pm 0.08$ & $* 1.0 \pm 0.1$ & $-5.5 \pm 1.9$ & $-1.8 \pm 0.09$ \\
\hline \multicolumn{6}{|c|}{ Phosphate Metabolism } \\
\hline$A n \mid 2 g 01910$ & similar to phytase PHYA3 Aspergillus fumigatus & $-1.5 \pm 0.1$ & $-1.6 \pm 0.3$ & $-21.1 \pm 2.5$ & $*_{-1} .0 \pm 0.1$ \\
\hline \multicolumn{6}{|c|}{ C-compound and carbohydrate metabolism } \\
\hline An09g00270 & alpha-galactosidase AGLC & $*_{-1.2} \pm 0.1$ & $-2.0 \pm 0.5$ & $-5.9 \pm 2.0$ & $* 1.1 \pm 0.3$ \\
\hline An09g00260 & alpha-galactosidase AGLC & $*-2.6 \pm 0.5$ & $-2.1 \pm 0.3$ & $-6.0 \pm 4.3$ & $* 1.1 \pm 0.2$ \\
\hline An0Ig0I540 & similar to alpha.alpha-trehalase TREA A. nidulans & $-3.0 \pm 0.6$ & $*_{-1.1} \pm 0.1$ & $-2.7 \pm 0.6$ & $* 1.2 \pm 0.02$ \\
\hline An0lg00780 & endo-I.4-xylanase XYNB & $-3.4 \pm 0.6$ & $* 1.5 \pm 0.4$ & $-4.3 \pm 0.9$ & $* 1.0 \pm 0.1$ \\
\hline An05g00930 & similar to mitochondrial malic enzyme MAEI & $-2.1 \pm 0.2$ & $* 1.2 \pm 0.1$ & $-4.0 \pm 1.0$ & $*_{-1} .0 \pm 0.04$ \\
\hline An 19900090 & similar to exo-beta-1.3-glucanase CMGI Coniothyrium minitans & $-2.6 \pm 0.3$ & $* 1.6 \pm 0.1$ & $-4.6 \pm 1.0$ & $* 3.7 \pm 0.06$ \\
\hline AnI lg04780 & similar to protein involved in active glycerol uptake GUPI & $-1.7 \pm 0.2$ & $* 1.2 \pm 0.2$ & $-2.4 \pm 0.3$ & $* 1.0 \pm 0.1$ \\
\hline
\end{tabular}

similar to protein involved in active glycerol uptake GUPI

$-1.7 \pm 0.2$

$* 12 \pm 0.2$

$* 1.0 \pm 0.1$ 
Table 2: Genes repressed by at least 2 treatments. (Continued)

An0Ig04250 similar to uroporphyrinogen decarboxylase HEMI2

$* I . I \pm 0.04$

$-1.6 \pm 0.1$

$-1.6 \pm 0.1$

\section{Cellular transport}

An $12 \mathrm{~g} 10320$

similar to high-affinity zinc transport protein ZRTI

$* 1.1 \pm 0.05$

$* 1.4 \pm 0.04$

$-2.2 \pm 0.04$

$-3.2 \pm 1.1$

An 16906740 similar to cadmium resistance protein YCF

$*-1.4 \pm 0.2$

$*-1.7 \pm 0.5$

$-1.7 \pm 0.2$

$-1.7 \pm 0.3$

Cescue. Defense and Virulence

An07g00570 similar to membrane protein PTHII Magnaporthe grisea

Anl8g00980 similar to membrane protein PTHII M. grisea

similar to membrane protein PTHII M. grisea

$*-1.1 \pm 0.1$

$*-3.0 \pm 0.5$

$*_{-1} .0 \pm 0.04$

$* 1.4 \pm 0.2$

$-2.7 \pm 0.06$

$-2.0 \pm 0.1$

An 16005920

similar to membrane protei

$* 1.1 \pm 0.2$

$-3.9 \pm 1.1$

$-4.6 \pm 0.2$

$-2.0 \pm 0.1$

Nucleotide/nitrogen and sulfur metabolism

An 10,00800 similar to purine nucleoside permease NUP Candida albicans

$-5.4 \pm 0.8$

$*-1.5 \pm 0.07$

$-31.9 \pm 2.7$

$+1.2 \pm 0.1$

An 1801220

similar to allantoate permease DAL5

$-1.6 \pm 0.1$

$* 1.6 \pm 0.2$

$-4.2 \pm 0.06$

$* 1.2 \pm 0.1$

Other

An07g06530

Anl6g05910

similar to multicopy suppressor SUR7

$* 2.0 \pm 0.4$

$* 1.7 \pm 0.2$

$-5.0 \pm 1.9$

$-1.6 \pm 0.1$

Anl lg09870

similar to putative cytochrome P450 A. fumigatus

$*-1.2 \pm 0.08$

$-2.3 \pm 0.5$

$-5.8 \pm 0.2$

$* 2.2 \pm 0.05$

Unclassified

similar to palmitoleyltransferase ERF2

$-1.6 \pm 0.1$

$* 1.4 \pm 0.2$

$-2.1 \pm 0.3$

$* 1.0 \pm 0.01$

An02g03570

AnI Ig07340

similar to membrane protein YBR I59w

$-2.1 \pm 0.2$

$*_{-1} .3 \pm 0.3$

$*-1.9 \pm 1.0$

$-1.6 \pm 0.2$

AnI2g09640

similar to hypothetical O-methyl transferase ENCK

An0lg09220

similar to hypothetical GTP cyclohydrolase

weakly similar to tyrosinase MELC2

An08g03760

similar to allergic allergen rAsp f 4 A. fumigatus

$* 1.3 \pm 0$.

$* 13 \pm 0.5$

$-4.2 \pm 0.6$

$-4.2 \pm 1.7$

$* 2.6 \pm 0.5$

$* 1.3 \pm 0.4$

$-3.3 \pm 0.2$

$-4.2 \pm 1.7$
$-1.9 \pm 0.5$

$*-2.1 \pm 0.5$

$* 2.1 \pm 0.2$

$-5.2 \pm 1.7$

$-1.8 \pm 0.4$

$*-2.3 \pm 0.6$

$*-1.1 \pm 0.3$

$-2.6 \pm 0$.

$-2.8 \pm 0.6$

$*-1.1 \pm 0.1 \quad *-1.3 \pm 0.07$

hypothetical protein

hypothetical protein

An06g01000

hypothetical protei

$* 1.2 \pm 0.2$

$*-17 \pm 11.3$

$-4.0 \pm 1.8$

$-2.4 \pm 0.3$

Anll 07020

$*-1.1 \pm 0.1$

$*-1.0 \pm 0.05$

$13.5 \pm 5.2$

$-1.8 \pm 0.1$

An02g08300

hypothetical protein

$* 1.3 \pm 0.3$

$* 1.2 \pm 0.02$

$-1.83 \pm 0.5$

$* 2.2 \pm 0.5 \quad *-1.7 \pm 0.3$

hypothetical protein

$1.8 \pm 0.2$

$*-1.7 \pm 0.3$

$-2.1 \pm 0.3$

$-1.8 \pm 0.2$

An $18 \mathrm{~g} 01000$

$*-2.4 \pm 0.5$

$* 1.1 \pm 0.1$

$-3.2 \pm 0.8$

$-8.6 \pm 0.9$

AnI3g0I520

hypothetical protein

$-1.5 \pm 0.1$

$*-2.9 \pm 0.2$

$1.3 \pm 0.1$

$-2.4 \pm 0.9$

$-2.4 \pm 0.5$

$* 1.2 \pm 0.3$

$-4.6 \pm 0.5$

hypothetical protein

An04g01690

$-2.1 \pm 0.4$

$*-1.0 \pm 0.3$

$*-1.0 \pm 0.4$

$-1.9+0.2$

An05g0I770

hypothetical protein

$-1.5 \pm 0.1$

$*-1.5 \pm 0.3$

$-2.0 \pm 0.5$

$*-1.8 \pm 0.07$

$-1.7 \pm 0.1$

strong similarity to allergen $r$ Asp $f 4 A$. fumigatus

similar to RTN2

$-1.8 \pm 0.2$

$*-1.2 \pm 0.2$

$-5.8 \pm 1.0$

$*-1.1 \pm 0.03$

$* 1.0 \pm 0.5$

$-1.9 \pm 0.2$

$* 1.3 \pm 0.2$

$+1.0 \pm 0.5$

An08g08600

hypothetical protein

$-2.6 \pm 0.4$

$*-1.0 \pm 0.0$

$-4.2 \pm 1.2$

$* 1.1 \pm 0.07$

An $12 \mathrm{~g} 10590$

similar to ER protein of unknown function

$-1.6 \pm 0.1$

$\mathrm{I} . \mathrm{I} \pm 0.03$

$-3.3 \pm 0.6$

$*-1.0 \pm 0.1$

$* 1.4 \pm 0.1$

$-2.1 \pm 0.3$

$1.0 \pm 0.02$

$* 1.0 \pm 0.1$

The fold changes in expression are indicated for all the treatments (Tun $=$ tunicamycin, $\mathrm{DTT}=$ dithiothreitol, $\mathrm{tPA}=$ production of $\mathrm{t}-\mathrm{PA}$ ) and are averaged over two experiments. Similarities are expressed in comparison with the Saccharomyces cerevisiae genome except when indicated. The symbol* indicates that the value does not meet one of the 3 restrictive criteria defined in the Method section. 

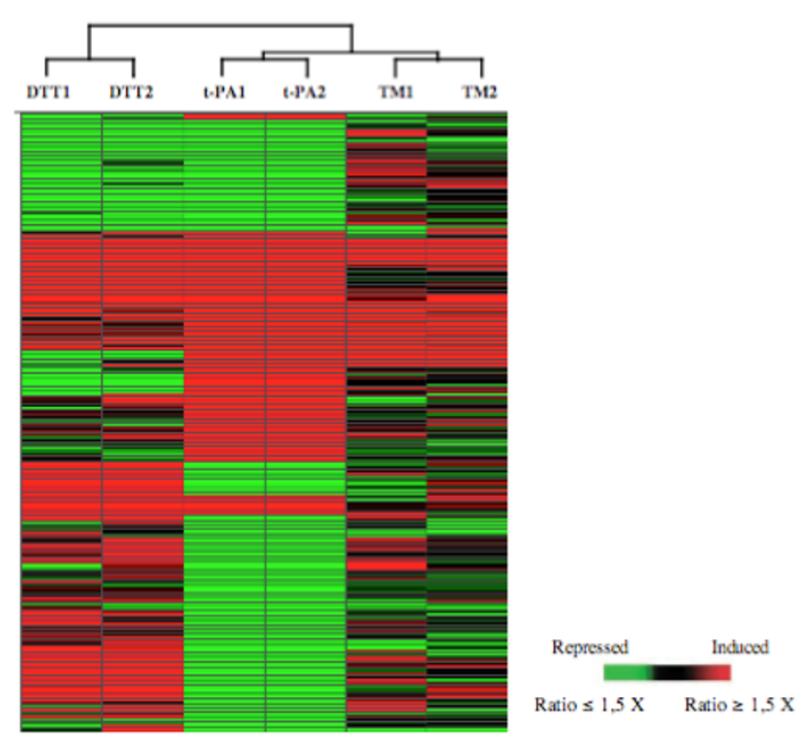

\section{Figure 2}

Hierarchical clustering of records in a dendrogram (tree graph) based on the similarity of the signal log ratios obtained in each of the duplicate stress studies. Records (I88) were selected based on differential expression in the tPA comparisons. This tree is representative for multiple clusterings performed using signals or signal log ratios. The genes have been rearranged into their cluster order and are represented on the vertical axis. The experiments are represented on the horizontal axis. The significance of the colour scale is indicated.

2) and 23 of these were common to both the t-PA and DTT conditions. Among the 61 genes that we found to be down-regulated by more than one stress condition, we identified 30 sequences containing a signal peptide, 6 genes encoding extracellular proteins and 4 genes related to the cell wall. At least 5 other genes involved in cell wall biosynthesis or function were additionally repressed by tPA production or tunicamycin treatment.

\section{Translational regulations during the ER stress response}

ER stress is known to lead to differential up- and downregulation of transcription, but differential translation has yet to be explored in filamentous fungi although a few reports are available with $S$. cerevisiae $[19,20]$. A direct analysis of translational control can be achieved by fractionation of cytoplasmic extracts in sucrose gradients, based on the methods described for polysome analysis [21], which involves size separation of large cellular components and monitoring the $\mathrm{A}_{254}$ across the gradient. This method enables the separation of free mRNPs (ribonucleoprotein particles) from mRNAs fully loaded with ribos-

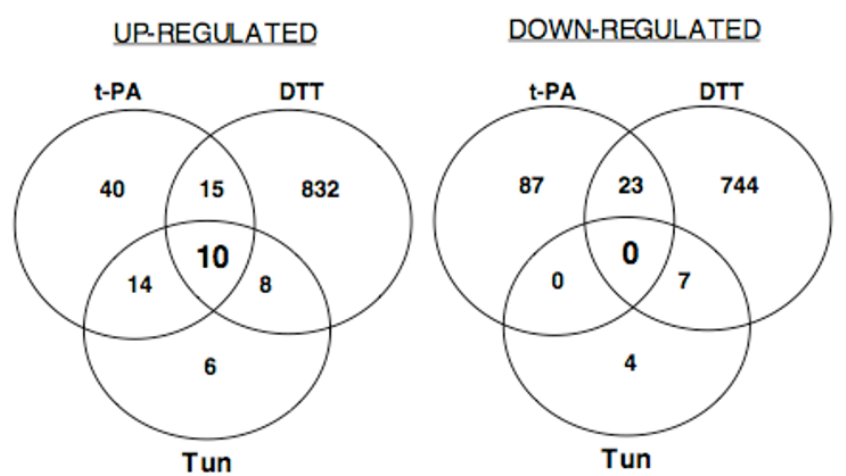

Figure 3

Venn diagrams of the numbers of overlapping and non-overlapping induced ( $\geq 1.5$ fold) or repressed ( $\leq \mathrm{I} .5$ fold) genes on the $A$. niger array after exposure to DTT or tunicamycin (Tun) and in the t-PA producing strain (t-PA).

omes (i.e. polysomes). As only polysomes represent actively translated transcripts, this fraction should be directly correlated with the set of de novo synthesized proteins in a particular cellular state and enables the determination of the translation efficiencies, which are characteristic for each transcript in a cell [22]. In addition, changes in the distribution of a given mRNA indicate how this translational efficiency can vary under different conditions. Because it is generally accepted that translational control predominantly occurs at the initiation step [23], the number of mRNA molecules engaged in polysomes should be a robust indicator of the synthesis rate of the corresponding protein.

Cytoplasmic extracts from DTT treated or untreated cells were loaded onto sucrose gradients and twenty fractions were collected from each one. RNA was extracted from each fraction and an aliquot was subjected to electrophoresis through a formaldehyde gel (Fig. 4B). As expected, $25 \mathrm{~S}$ and $18 \mathrm{~S}$ ribosomal RNAs were the prominent species. As described $[21,24]$, the assignment of $\mathrm{OD}_{254}$ peaks corresponding to the $40 \mathrm{~S}$ and $60 \mathrm{~S}$ subunits and to intact ribosomes was confirmed with $18 \mathrm{~S}$ and $25 \mathrm{~S}$ RNAs distribution (Fig. 4A). There was no marked net change in the absorbance profile of DTT-treated samples compared to the control, indicating that the ER stress did not cause a global change of translational activity.

Furthermore, the distribution of spliced $\left(h a c A^{i}\right)$ and unspliced hacA mRNA ( $h a c A^{u}$ ) over the gradients was analysed by RT-PCR with hacA primers amplifying a fragment across the $20 \mathrm{nt}$ intron region (Figure 4C). In A. niger control samples, a low level of $h a c A^{u}$ transcripts was detected, which sedimented with both polysomal and non-polyso- 


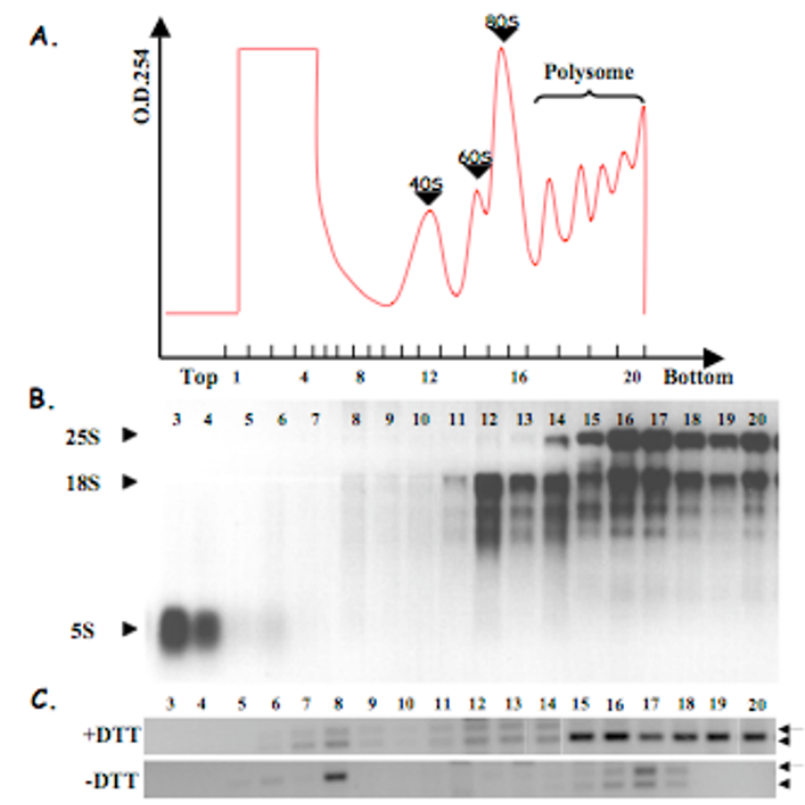

\section{Figure 4}

(A) Representative absorbance profile for RNA separated by velocity sedimentation through a 15-60\% sucrose gradient. Fractions are numbered from the top to the bottom of the gradient. (B) RNA was extracted from each fraction and subjected to electrophoresis through a formaldehyde gel. The ribosomal RNA distribution profile (25S, I8S and 5S rRNA; indicated by arrowheads) enables the the assignment of $\mathrm{OD}_{254}$ peaks, corresponding to the $40 \mathrm{~S}$ and $60 \mathrm{~S}$ ribosomal subunits and to intact ribosomes (80S). (C) RT-PCR analysis with hacA primers were performed from each fraction of collected gradients from treated and non-treated cells. The full length hacAu mRNA (arrow) as well as low-molecular-weight version of hacA (arrowhead) can be visualized.

mal fractions. Low level amplifications from the spliced form were also obtained in the polysomal fractions, suggesting that splicing occurs to a low level even in nonstressed samples. In DTT-treated samples, spliced and unspliced transcripts were detected but the spliced form was clearly predominant and was mainly recovered from the bottom of the gradient and therefore was ribosomeassociated.

RNA fractions were pooled into non-polysomal and polysomal samples according to $\mathrm{OD}_{254}$ profiles and were used as a matrix for GeneChip hybridisation. Translational regulation of each mRNA was assessed by measuring the relative proportions of each mRNA in the polysomal and non-polysomal RNA fractions and then determining changes to this ratio. The ratio was determined by calculation of "DTT-induced shift from non-polysomal to polys- omal samples": for each transcript microarray expression values were analysed by calculating (DTT-treated polysomal/DTT-treated non-polysomal)/(control polysomal/ control non-polysomal). Several of these translational regulated genes are listed in the Table 3 . Twenty six genes showed enhanced translation during DTT-treatment (a > 2 fold shift from non-polysomal to polysomal fractions). Several of the predicted proteins function as part of the secretory system including a signal peptidase and a proteasome protein. Two hundred and fifty three genes showed reduced translation ( $\mathrm{a}<2$ fold shift from polysomal to non-polysomal fractions) including 108 hypothetical protein encoding genes. DTT treatment resulted in translational repression of a large number of genes with functions in ribosomal biogenesis and assembly. Included were several mRNAs encoding both large and small ribosomal subunit proteins (RPL and RPS families). This result may support a hypothesis of a translational repression as a mechanism of reducing ER throughput during ER stress. Three RPS and 2 RPL encoding genes are included in Table 3, but 9 other RPS and 23 other RPL were affected by this regulation, suggesting that RP mRNAs were coordinately regulated at the translational level. We also found that several mRNAs encoding secreted proteins were also redistributed from polysomes to monosomes and untranslated mRNPs. These results suggest that, in addition to the transcriptional repression mechanism called RESS, another feed-back mechanism could occur upon ER stress at the translational level and lead to a reduced amount of new protein translocated into the ER lumen. Our results also indicate that DTT repressed the translational activity of a number of genes belonging to other functional categories including the ERAD pathway, lipid metabolism or cell wall biogenesis (Table 3).

\section{Discussion}

This is the first complete analysis of ER stress in A. niger. It has been made possible by the availability of the complete annotated genome sequence [13] and genome-wide GeneChips, which include built-in control sequences. The global ER stress response has already been reported in $S$. cerevisiae [7] but equivalent studies in the filamentous fungi have been hampered by the lack of complete genome sequences and the non-availability of gene arrays. Such bottlenecks are being removed and we have already seen the description of ER stress responses in Trichoderma reesei $[25]$ and $A$. nidulans using arrays that cover approximately one third of the predicted open reading frames [12]. A. nidulans is scarcely exploited for its capacity to secrete enzymes because other filamentous fungi, including A. niger, have proved to hold advantages in terms of the range and yield of secreted enzymes. Previous analyses of secretion stress in A. niger have relied either on analysis of specified target genes $[2,26]$ or have used cDNA subtraction libraries $[18,27]$ which, in contrast to GeneChips, 


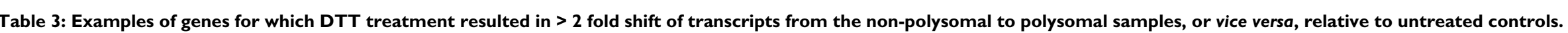

AnI $5 g 01130$

AnOlgI4260

An 17g00270

Translation

An02g13840

Anl8g05810

An08900970

Anl Ig09570

An I 2g04860

AnOlg02880

An I8g04570

An02g09260

An 18g04840

AnI5g00750

An07g02650

Proteolytic degradation

Anl Ig01760

An02g07010

Lipid metabolism

An08g10II0

An03g064I0

An $12 \mathrm{~g} 01890$

An02g10350

An07g09570

Cell Wall

An03g02400

An06g01550

Anl I. 00270

An02g02360

Secreted proteins

AnI2g01910

An03.06550

An02gl 3220

An09g00270

An02g01550

An02g04690 simila delta subunit of the coatomer delta-coat protein COPD (Bos. taur

From polysomal to non-polysomal fractions

similar to cytoplasmic ribosomal protein of the small subunit $\mathrm{S} 9(\mathrm{H}$. sapiens)

similarity to cytoplasmic ribosomal protein of the small subunit S26 (H. sapiens)

$$
\text { ribosomal protein of the small subunit rps } 28
$$

similar to cytoplasmic ribosomal protein of the large subunit L37.b

similar to cytoplasmic ribosomal protein of the large subunit $L 30$

similar to cytoplasmic ubiquitin/ribosomal fusion protein CEP52

similar to cleavage/polyadenylation factor IA subunit CLP similar to nucleolar protein NOP5

similar to elongation factor I alpha (Podospora anserina)

Similar to elongation factor I-gamma I TEF3

similar to translation elongation factor 3 YE3

similar to proteasome $20 \mathrm{~S}$ subunit PRE2

similar to ubiquitin UBII (A. nidulans)

similar to lipid transfer protein POXI8 (C. tropicalis)

similar to methyl sterol oxidase ERG25

similar to squalene synthase ERG9 (C. utilis)

similar to farnesyl-pyrophosphate synthase FPPS

similar to phosphatidate cytidylyltransferase CDSI

similar to hydrophobin DEWA (A. nidulans)

similar to glucan synthase FKS (Paracoccidioides brasiliensis)

similar to lanosterol I 4 alpha-demethylase CYP5I (H. sapiens)

similar to chitin synthase (A. nidulans)

Polysomal/non-polysomal Control polysomal DTT treated

DTT induced shift

0.79

1.79

0.47

0.51

0.71

0.57

0.37

0.67

0.71

2.16

2.96

3.79

1.1

0.96

1.23

1.01

1.90

0.84

0.51

0.46

0.64

similar to phytase PHYA3 (A. fumigatus)

Glucoamylase GLAA

similar to lysophospholipase phospholipase B (P. notatum) alpha-galactosidase AGLC

similar to serine protease (Coccidioides immitis)

similar to serine-type carboxypeptidase I CDPS (A. saitoi)
0.64

0,26

0.68

1.28

27.28

11.22

3.48

8.33

4.18

4.61

1.56

9.22

6.02

5.35

23.88

20.52

7.5

4.04

2.84

2.21

4.13

1.73

1.59

1.33

1.44

0.96

4.03

17.69

2.90

1.65

3.56
7.20

3.04

2.63

2.45

57.91

22,03

4.91

14.62

6.92

2.20

4.34

3.2

2.47

8.0

5.42

7.12

4.23

232

2. 18

2.17

2.06

3.10

2.89

2.25

D The DTT induced shift was determined by calculating (DTT treated polysomal/DTT treated non-polysomal)/(control polysomal/control non-polysomal). 
reveal only a small fraction of differentially expressed genes.

A low variation (a technical standard deviation of 0.16 and a biological standard deviation of 0.25 on average for the signal log ratio of 'present' genes) was shown for GeneChip replicates (data not shown). Generally, dependent on growth conditions, 5000-6000 genes were found to be expressed, with 10-20 genes detected as false positives in a single experiment. In any global transcriptomic study it is essential to have biological replicates that provide assurance of the validity of the conclusions reached. The biological replicates used in this study showed a small variation compared to the experimentally induced variation except for the tunicamycin study where the experimentally induced variation was small. Both for the chemostat-cultivated tPA strain and the shake-flaskcultivated tunicamycin-exposed cells, less than $4 \%$ and $1 \%$ of the expressed genes, respectively, were determined as changed by at least 1.5 -fold.

We confirmed that each of the stress conditions led to induction of the UPR as judged by the transcriptional induction of $A$. niger genes known to be affected by ER stress, bipA [28] and pdiA [29]. In addition, we confirmed splicing of the 20bp intron in the A. niger hacA mRNA $[10,16]$. It has recently been established that the UPR does not just involve the simple switch based around the synthesis of the mediating transcription factor but that there is further complexity under some conditions [30-32]. In A. niger [10], Trichoderma reesei [11] and S. cerevisiae [33] it is known that ER stress can lead to the transcriptional down-regulation of some genes encoding secreted proteins and this effect, termed repression under ER stress (RESS) [11], may be independent of the UPR [10]. ER stress due to over-expression of membrane proteins can elicit the transcriptional up-regulation of bipA without apparent splicing of the hacA intron in A. niger [34]. This effect, together with RESS, indicates that there is complexity in ER stress responses in filamentous fungi. Our results confirm the existence of the RESS mechanism in A. niger since the transcription of several major secreted proteins encoding genes was clearly repressed by at least 2 treatments. Moreover, in common with the data generated in Arabidopsis thaliana [35], many repressed genes in A. niger encode membrane proteins and transporter proteins that may be essential for the maintenance of cellular ion homeostasis. Thus, the list presented in the additional file 6 contains several putative zinc, iron, calcium and manganese transporters and the zinc-regulated transcription factor Zap1, which were mainly repressed by t-PA production. Previous studies showed that both calcium [36] and zinc [37] are required for ER function in yeast and that their deficiency induces the UPR.
Analysis of the impact of secretion stress on the genes encoding components of the secretory system in A. niger is summarized in Fig. 5. Few of the translocon genes (encoding components of both the co- and post-translational translocation system), which were largely not represented in the A. nidulans arrays [12], were induced under two or more stress conditions. The signal sequence recognition system was transcriptionally unaffected except in one component but there was more response from components of the signal peptidase complex. Several of the translocon genes and one component of signal peptidase were induced under UPR in S. cerevisiae [7]. A. niger homologues of the S. cerevisiae SEC11, SPC2 and SPC3 were all up-regulated under ER stress. Of the predicted ERresident chaperones, bipA was induced under all conditions as expected [28]. The calnexin-encoding $c l x A$ gene [38], where the production of prochymosin was previously shown to induce its transcription, was shown here to be additionally induced by both DTT and tunicamycin. A homolog of the S. cerevisiae LHS1 gene, lhsA, has not been previously described in $A$. niger but was annotated in the genome of $A$. niger and represented on the GeneChips. As with bipA, lhsA was transcriptionally up-regulated under all 3 conditions compared to controls. In S. cerevisiae, the chaperone cycle involves products encoded by KAR2 (encodes a Bip-like chaperone) and LHS1 (where the ATPase activities of these two Hsp70p chaperones are coordinately regulated) as well as nucleotide exchange activity provided by Sil1p and DNAJ proteins such as Scj1p and Jem 1p [39]. The ER-resident chaperone and foldase system was generally induced under UPR conditions in S. cerevisiae even if KAR2 and PDI1 failed to meet the stringent criteria applied [7]. Although $l h s A$ has been identified here as a stress-responsive gene, as was at least one DNAJ protein, no candidate genes have been found for the nucleotide exchange factor homolog of yeast SIL1. On the presumption that this functionality exists, it may reside in a protein with low sequence identity to Sillp or in another component, e.g. LhsA. A putative ortholog of a mammalian p58-encoding gene (similarity to human p58 with e value of $4 \mathrm{e}-59$, showing $32 \%$ amino acid identity over 450 residues) was induced by both t-PA and tunicamycin. P58 is involved in translational regulation in mammalian cells, its induction is mediated by ATF6 and it plays a role in regulating the PERK/eIF2alpha/ATF4 pathway [40]. Homologs of PERK and ATF4/6 appear to be absent from A. niger so the role of the putative p58 in A. niger is intriguing.

Manipulations of the ER lumenal environment have been previously examined in Aspergillus with the aim of improving the secreted yield of heterologous proteins. This has been attempted with individual genes such as bipA [41] and pdiA [42] as well as through manipulation of the UPR [43]. Detailed knowledge of the responses of 
individual genes to different stresses should permit refinements to these approaches that would be more consistently beneficial. The complexity of the chaperone cycle has already been mentioned but the formation of disulfide bonds is another key example. Although the pdiA gene encodes the principal foldase in A. niger [29], other genes encoding members of this foldase/isomerase family have also been described [44,45]. A fuller description of their responses to different stresses is provided by the GeneChip studies described here and shows that all three foldase genes are up-regulated by all stresses except for tigA by DTT. The contributions to foldase activity provided by the three identified lumenal foldases (PdiA, TigA, PrpA) is not known although, in S. cerevisiae, Pdi1p is known to contribute more activity than the other yeast foldases [46]. In S. cerevisiae, Ero1p is an essential lumenal protein involved in electron transfer during the formation of disulfide bonds and its homolog in A. niger, eroA, was induced under all stress conditions. Interestingly, Ero1p is retained in the lumen by attachment to the ER membrane in a manner that is not wholly understood [47] whereas the A. niger EroA is predicted to contain a conventional Cterminal ER retention sequence. The receptor for retention of C-terminal (H/K)DEL-containing proteins (Erd2p in $S$. cerevisiae) was induced under ER stress in both A. niger and $S$. cerevisiae [7]. In other areas, several genes involved in glycosylation of secretory proteins were induced under ER stress in both S. cerevisiae [7] and in A. niger (Fig. 5) and included a homolog of the yeast RFT1 gene that is responsible for translocation of lipid-linked glycan intermediates into the ER [48].

In fungi, the only reported translational control during the UPR concerns the expression of the yeast transcription factor Hac1p [20]. This control is mediated by a base-pairing interaction between an intron at the $3^{\prime}$ end and the $5^{\prime}$ untranslated region, which represses mRNA translation. Splicing of this unconventional intron is sufficient to relieve this translational block. It has been reported that the HAC1u mRNA in yeast was stable, located in the cytosol and associated with ribosomes, yet did not produce protein, indicating that the ribosomes engaged on the mRNA were stalled and that translation was attenuated at the elongation step [20]. Our results showed that $h a c A^{u}$ mRNA could also sediment in non-polysomal fractions, suggesting that translation of this mRNA species may be blocked at the translational initiation step in addition to the previously reported elongation step, as also shown in yeast [49]. DTT treatment resulted in translational repression of a large number of genes with functions in ribosomal biogenesis and assembly (Table 3 ). This result may support the hypothesis of a translational repression as a mechanism of reducing ER throughput. It is known that the abundance of RP mRNAs rapidly decreases when yeast cells encounter stress situations

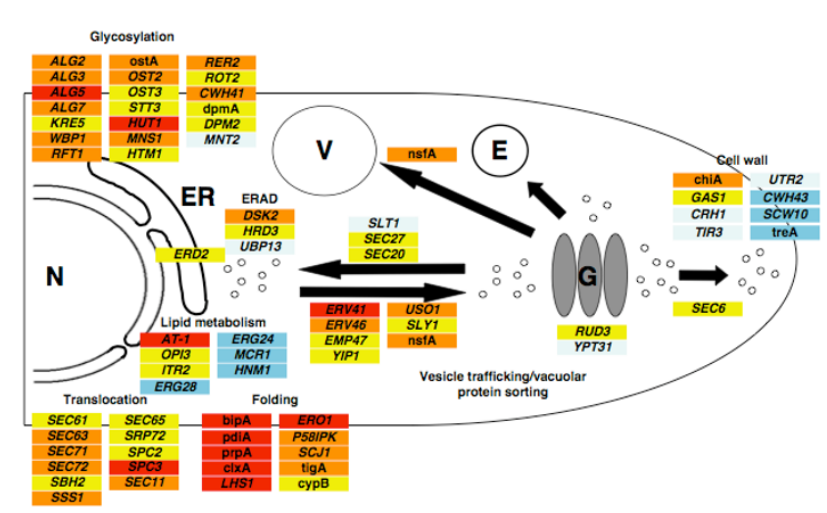

\section{Figure 5}

Model of the secretory pathway under different ER stress conditions (t-PA secretion, tunicamycin and DTT) together with examples of genes that are transcriptionally induced or repressed. The $A$. niger gene designation is provided where previously known or, otherwise, the $S$. cerevisiae gene name is provided. Red, genes up-regulated by 3 conditions; orange, genes up-regulated by 2 conditions; yellow, genes up-regulated by I condition; light blue, genes down-regulated by I condition; blue, genes down-regulated by 2 conditions. $\mathrm{N}$, nucleus; $E R$, endoplasmic reticulum; $E$, endosome; $V$, vacuole; $\mathrm{G}$, Golgi. ERAD is ER-associated degradation.

[50,51]. We also found that several mRNAs encoding secreted proteins were also redistributed from polysomes to monosomes after DTT exposure and the gene glaA encoding glucoamylase, which is a major secreted protein in A. niger, was one of them. Therefore, in addition to the transcriptional down-regulation of glaA due to DTT stress, our results suggest that a post-transcriptional regulatory mechanism negatively affects the translation of glaA mRNA in A. niger. For the first time in filamentous fungi, these results suggest the existence, in addition to the RESS, of another feed-back mechanism that occurs upon ER stress at the translational level and leads to a reduction in the amount of new protein translocated into the ER lumen.

\section{Conclusion}

This is the first complete analysis of ER stress in A. niger, a filamentous fungus used commercially for the secreted production of a range of native and heterologous proteins. It has been made possible by the availability of the complete annotated genome sequence and genome-wide GeneChips. We induced ER stress either by chemical treatments of the wild-type cells or by expressing a heterologous protein. Following the induction of ER stress, A. niger cells display a diverse array of adaptative changes in gene expression at both the transcriptional and translational levels. The transcriptional responses to each stress were compared and the overlaps common to these conditions led to the identification of robust sets of induced or 
repressed genes Thus, a range of transcriptional targets has been identified as putative candidates for secretion stressrelated genes, including a large number of genes encoding components of the secretory system. Moreover, by combining polysomal fractionation with DNA GeneChip analyses, we have focused on the translational activity of several individuals mRNAs following DTT exposure. Although the observed polysome profiles were similar under control and ER stress conditions, we confirmed the post-transcriptional control of hacA expression and highlighted that differential translation could also occur during ER stress at least for some genes encoding secreted or ribosomal proteins. Many of the genes identified in this study provide targets for improving $A$. niger as a cell factory for protein production.

\section{Methods \\ Strains, culture conditions and treatments}

The AB4.1 strain, a pyrG- strain that is auxotrophic for uridine [52], was used for the chemical treatment experiments. A protease-deficient strain (D15) of A. niger, derived from strain AB4.1, was used as a host for the production of human tissue plasminogen activator (t-PA). The t-PA was produced in the recombinant strain D15\#25 as a fusion protein with the catalytic domain of the native glucoamylase protein. The gene encoding this fusion protein was expressed under control of the constitutive promoter for glyceraldehyde-3-phosphate dehydrogenase $(g p d A)$.

The A. niger strains were maintained on potato dextrose agar slopes (Oxoid). All AB4.1 cultures were supplemented by $10 \mathrm{mM}$ uridine (Sigma). Slopes were incubated at $30^{\circ} \mathrm{C}$ until the cultures had conidiated and spores were resuspended in $0.1 \%$ (v/v) Tween 20 (Sigma). Liquid batch cultures were inoculated with $3 \times 10^{5}$ spores/ $\mathrm{ml}$, grown for $44 \mathrm{~h}$ in $100 \mathrm{ml}$ of starch-containing ACMN/ $\mathrm{N} / \mathrm{P}$ medium [53] in $250 \mathrm{ml}$ conical flasks at $25^{\circ} \mathrm{C}$ and shaken at 150 r.p.m. Batch AB4.1 cultures were treated with ER stress reagent (DTT or tunicamycin) for $2 \mathrm{~h}$. DTT stock was prepared in water and tunicamycin stock in DMSO. DTT or tunicamycin were added to the liquid medium at a final concentration of $20 \mathrm{mM}$ or $10 \mu \mathrm{g} / \mathrm{ml}$, respectively. Control cultures had an equivalent volume of sterile water or DMSO added. For tunicamycin treatment with germlings of $A$. niger, fresh spore cultures were prepared as previously described and incubated for $5 \mathrm{~h}$. A sample was taken for microscopic examination of germination, which was in excess of 90\%. Cultures were treated by tunicamycin $(10 \mu \mathrm{g} / \mathrm{ml})$ or DMSO for $1 \mathrm{~h}$, after which the germlings were harvested by filtration and frozen in liquid nitrogen. Continuous cultures were carried out in an Applikon (FT Applikon Ltd., Tewkesbury, UK) bioreactor (2.1 l full working volume) according to published methods [54]. The medium (one tenth strength SCM con- tained $5 \mathrm{gl}^{-1}$ maltose as the carbon source. Cultures were inoculated with $5 \times 40 \mathrm{ml}$ shake flask pre-cultures, which had been growing in medium containing $10 \mathrm{gl}^{-1}$ of maltose for approximately 24 hours. Cultures were maintained at $30^{\circ} \mathrm{C} \pm 1{ }^{\circ} \mathrm{C}$ and $\mathrm{pH} 5.5 \pm 0.1$, agitated at 1200 rpm with a 3 six-bladed ( $48 \mathrm{~mm}$ diameter) Rushton turbine impeller and aerated with $0.7 \mathrm{vvm}$ ( 1 air [l culture]$\left.{ }^{1} \mathrm{~min}^{-1}\right)$. Foaming was controlled by continuous addition of a mixture of polypropylene glycol (PPG) of different molecular weights PPG 1025 (BDH): PPG 2025 (BDH): FoamMaster PPG (mixed molecular weight; Henkel Performance Chemicals, Leeds, UK) in the ratio $2: 2: 1$ [15] to give a final concentration of approximately $0.01 \%(\mathrm{v} / \mathrm{v})$ PPG. The dilution rate was kept constant at $0.080 \pm 0.006$ $\mathrm{h}^{-1}$. In order to reduce the degree of attachment of biomass to the surfaces inside the bioreactor, the impeller speed was increased to $1500 \mathrm{rpm}$ once a day for about 15 minutes after sampling. The maximum specific growth rate $\left(\mu_{\max }\right)$ during the batch growth phase in bioreactors was estimated from the $\mathrm{CO}_{2}$ output using an ADC 7000 infrared Gas Analyzer (The Analytical Development Co. Ltd.; U.K) and $\mathrm{CO}_{2}$ evolution rate was also measured online throughout the whole experiment to monitor steady state.

\section{Total RNA extraction}

Total RNA was prepared from each condition according to the TRIzol reagent protocol (Invitrogen). Each sample was treated with RQ1 RNase-Free DNase (Promega) according to the manufacturer's instructions, followed by a phenol:chloroform extraction and ethanol precipitation. An additional cleanup was performed using the RNEasy Mini Kit (Qiagen), following the manufacturer's RNA Clean-up protocol.

\section{Polysome analysis}

Ribosomal fractions were prepared according to the method described for polysome analysis [21], modified as follows. At the time of harvest, cycloheximide was added to a final concentration of $0.1 \mathrm{mg} / \mathrm{ml}$ to trap elongating ribosomes. The cultures were swirled rapidly and chilled on ice for 10 minutes. Fungal material was pelleted by centrifugation at $11000 \mathrm{~g}$ for $10 \mathrm{~min}$ at $4^{\circ} \mathrm{C}$. The pellet was then resuspended in $5 \mathrm{ml}$ of polysome extraction buffer (20 mM Tris-HCl pH 8.0, $140 \mathrm{mM} \mathrm{KCl}, 1.5 \mathrm{mM}$ $\mathrm{MgCl}_{2}, 1 \%$ Triton X-100, $0.1 \mathrm{mg} / \mathrm{ml}$ cycloheximide, 1.0 $\mathrm{mg} / \mathrm{ml}$ heparin, $0.5 \mathrm{mM}$ DTT) and sedimented. This washing step was repeated and cells were frozen in liquid nitrogen and stored at $-80^{\circ} \mathrm{C}$.

Approximately $0.25 \mathrm{~g}$ of cells was ground in liquid nitrogen with a mortar and a pestle, and the powder was resuspended in $750 \mu \mathrm{l}$ of ice-cold polysome extraction buffer. Excess cell debris were removed by sedimentation at 4000 $\mathrm{g}$ for $5 \mathrm{~min}$ at $4^{\circ} \mathrm{C}$. The supernatant was clarified by fur- 
ther centrifugation $\left(12000 \mathrm{~g}, 10 \mathrm{~min}, 4^{\circ} \mathrm{C}\right)$. Each sample was loaded on an $8 \mathrm{ml} 15$ to $60 \%$ (w/v) sucrose gradient and sedimented at $150000 \mathrm{~g}(55000 \mathrm{rpm})$ and $4^{\circ} \mathrm{C}$ in a Beckman MLA-80 rotor for $135 \mathrm{~min}$. Sucrose solutions were prepared in $50 \mathrm{mM}$ Tris acetate $\mathrm{pH} 7.0,50 \mathrm{mM}$ $\mathrm{NH}_{4} \mathrm{Cl}, 12 \mathrm{mM} \mathrm{MgCl} 2,1 \mathrm{mM}$ DTT. The gradient was fractionated with a density gradient fractionator (Foxy Jr. Fraction Collector, ISCO), whilst monitoring absorbance at $254 \mathrm{~nm}$ using a UA-6 UV detector (ISCO). $0.5 \mathrm{ml}$ fractions were collected from the top of the gradient directly into $1 \mathrm{ml}$ volume of $6 \mathrm{M}$ guanidine hydrochloride. RNA was precipitated by adding an equal volume of $100 \%$ ethanol and resuspended in Tris-EDTA (TE, $\mathrm{pH}$ 8.0). The RNA was again precipitated by addition of $50 \mu \mathrm{l}$ of $3 \mathrm{M}$ sodium acetate (pH 5.2) and $1 \mathrm{ml}$ of $100 \%$ ethanol, and resuspended in $\mathrm{TE}(\mathrm{pH} 8.0)$.

For RNAs destined for microarray analyses, the polysomal fractions and non-polysomal fractions were pooled respectively. Each fraction was treated with RQ1 RNaseFree DNase (Promega) and was again cleaned up by applying the samples to an RNeasy mini column (Qiagen).

\section{Northern analysis and RT-PCR amplification analyses}

Northern blot hybridization was performed using the formaldehyde-based system NorthernMax as described by manufacturer and transfer was achieved to BrightStar-Plus membranes (Ambion Inc., Austin, Tex.). [ $\alpha-32 P] d U T P-$ labeled antisense RNA probes were prepared with the Lig'nScribe and the Strip-EZ RNA kits according to the manufacturer's instructions (Ambion Inc., Austin, Tex.). Coding sequences for differentially expressed genes were downloaded from the DSM A. niger database [13] and PCR primers for each selected gene were designed with Primers 3.0 (Whitehead Institute, Massachusetts Institute of Technology, Boston, MA). The PCR primers used to generate probes for Northern blotting and for RT-PCR (including for RT-PCR across the hacA mRNA intron) are listed in Table 4. Probes were generated from genomic DNA of A. niger strains by PCR amplification. The PCR conditions were as follows: an initial denaturation of $94^{\circ} \mathrm{C}$ for 3 min was followed by 30 cycles of $94^{\circ} \mathrm{C}$ for 30 $\mathrm{s}, 57^{\circ} \mathrm{C}$ for $1 \mathrm{~min}$ and $72^{\circ} \mathrm{C}$ for $1 \mathrm{~min}$. For densitometric analysis, signals were quantified with a Fuji film BAS2000 phosphorimaging system.

Reverse transcriptions were carried out using the SuperScript II Reverse Transcriptase system (Invitrogen, Life Technologies) according to the manufacturer's instructions.

\section{Genome sequence and microarray analysis}

Processing of mRNA to cDNA, labelling, hybridization to A. niger Affymetrix GeneChips (Affymetrix, Inc., Santa Clara, CA) and fluorescence scanning were performed at the Nottingham Arabidopsis Stock Center (NASC, Loughborough, UK) Affymetrix facility. The Affymetrix Microarray Suite version 5.0 program was used to normalize microarray data and to calculate signal intensity, detection $\mathrm{p}$-value, signal log ratio and change $\mathrm{p}$-value using the statistical algorithms of version 5.0. The detection p-value was used to assign a call whether a measured transcript was detected at significant level as $\mathrm{P}$ (present), below detection level as A (absent) or in-between as M (marginal). The change p-value based on Wilcoxon's Signed Rank test of 12 probe pair comparisons, was used to provide a measure of the likelihood of change between two GeneChips and direction, assigning a change call as I (induced), D (decreased) or NC (not changed). The signal and signal log ratio were computed by taking probe pair intensities (each transcript is represented by 12 probe pairs) of one GeneChip or across two GeneChips, respectively. For each treatment condition, for all 14555 probe sets, the calculated signal log ratios (in base 2) were converted into fold change of mRNA level relative to untreated or control cultures, to make interpretation more intuitive.

In total, 12 Affymetrix Genechips measurements were obtained with total RNA samples from which 6 duplicated comparisons between the treated samples and the respective control were analysed: 2 for the DTT treatment, 2 for the tunicamycin treatment and 2 for the t-PA produc-

Table 4: Primers for probe generation by PCR and for RT-PCR.

\begin{tabular}{|c|c|c|}
\hline Gene & Primer pairs & Amplicon size (bp) \\
\hline bipA $A^{1,2}$ & 5'-CAGAGACAGGCCACCAAGGACGCT-3' 5'-CGAACTTGGCGCGGGTGAGGGTCT-3' & 445 \\
\hline pdiAl & 5'-TATCTTTGCCGAGACCAAGG-3' 5'-AACAGGTTCCGACTTGATGC-3' & 298 \\
\hline$p d i A^{2}$ & 5'-TGATACCGAGTCTGAGTTA-3' 5'-CTCGATTCTGTTTGCCTAGC-3' & 303 \\
\hline$A n 02 g / 341011$ & 5'-CGCATCCTACCCATACTCGT-3' 5'-GGAACCAGCGATTAGCAAAG-3' & 280 \\
\hline hacA ${ }^{2}$ & 5'-СТTСТССТАСССТAACTCCT-3' 5'-TCAAAGAGAGAGAGGGCAC-3' & 397 \\
\hline act $/ 1$ & 5'-GCCTTCTACGTCTCCATCCA-3' 5'-GAACAGAGCCTCAGGAGCAC-3' & 396 \\
\hline$a c t / 2$ & 5'-TCATGATCGGTATGGGTCAG-3' 5'-ACGATGTTGCCGTACAGATC-3' & 765 \\
\hline
\end{tabular}

I: primers designed for blot probes

2: primers designed for RT-PCR 
tion. Genes were considered to be differentially expressed specifically by each treatment if (i) expression levels changed by at least 1.5 fold in both independent replicates, (ii) the mRNAs were assigned at least $2 \times$ p-values over the 4 detection calls, and (iii) the change call in gene expression was in the same direction (increased or decreased) in duplicated experiments. Additionally, a total of 8 Affymetrix Genechips were hybridized with polysomal and non-polysomal samples treated or not by DTT, each conditions being analysed twice. The Spotfire program was used to determine the list of genes meeting these restriction criteria and to determine the overlap in the gene sets. Finally, manual inspection was performed for each selected entry group to remove repeated or control entries. The Spotfire Decision Site for Functional Genomics was used to perform hierarchical clustering (Euclidean distance, UPGMA) and to group records according to their similarity in a dendrogram.

The A. niger genome and gene sequence can be accessed through [55].

\section{Authors' contributions}

This study was carried out predominantly by TG in the laboratory of DA. TG was funded by DSM Food Specialities and NvP was directly involved in the analysis of Affymetrix GeneChip data. Detailed discussions on this analysis were held at DSM and involved HS, NvP, TG and DA. KL and GR provided samples of A. niger biomass producing tPA. TGoosen and CvdH collaborated by undertaking some stress studies. All authors contributed in discussions of the approach and interpretation of results.

\section{Additional material}

\section{Additional file 1}

Scaling (normalization) factors for the GeneChips used in the stress studies. The figure provided show that overall signal intensities were comparable throughout all GeneChips.

Click here for file

[http://www.biomedcentral.com/content/supplementary/1471-

2164-8-158-S1.doc]

\section{Additional file 2}

Overall variations in gene expression levels induced by tunicamycin treatment. In panel A, signals of tunicamycin treatment ( $y$-axis) vs DMSO ( $x$ axis). In panel $B$, distribution of signal log ratio's $\left({ }^{2} \log \right)$.

Click here for file

[http://www.biomedcentral.com/content/supplementary/14712164-8-158-S2.tiff]

\section{Additional file 3}

Overall variations in gene expression levels induced by $t$-PA expression. In panel $A$, signals of $t$-PA treatment ( $\gamma$-axis) vs control strain ( $x$-axis). In panel B, distribution of signal log ratio's ( $\left.{ }^{2} \log \right)$.

Click here for file

[http://www.biomedcentral.com/content/supplementary/14712164-8-158-S3.tiff]

\section{Additional file 4}

Overall variations in gene expression levels induced by DTT treatment. In panel A, signals of DTT ( $y$-axis) vs control strain ( $x$-axis). In panel B, distribution of signal log ratio's $\left({ }^{2} \log \right)$.

Click here for file

[http://www.biomedcentral.com/content/supplementary/14712164-8-158-S4.tiff]

\section{Additional file 5}

Genes induced by tPA and/or tunicamycin treatments. The fold changes in expression are indicated for all the treatments (Tun = tunicamycin, $D T T=$ dithiothreitol, $t P A=$ production of $t-P A)$. Similarities are expressed in comparison with the Saccharomyces cerevisiae genome except when indicated. The symbol* indicates that the value do not meet the defined restrictive criteria. The genes induced by the three treatments are marked in bold.

Click here for file

[http://www.biomedcentral.com/content/supplementary/1471-

2164-8-158-S5.doc]

\section{Additional file 6}

Genes repressed by tPA and/or tunicamycin treatments. The fold changes in expression are indicated for all the treatments (Tun $=$ tunicamycin, $D T T=$ dithiothreitol, $t P A=$ production of $t-P A)$. Similarities are expressed in comparison with the Saccharomyces cerevisiae genome except when indicated. The symbol* indicates that the value do not meet the defined restrictive criteria.

Click here for file

[http://www.biomedcentral.com/content/supplementary/14712164-8-158-S6.doc]

\section{Acknowledgements}

We thank the Biotechnology and Biological Sciences Research Council for contributing financial support to DBA, GDR and KL.

\section{References}

I. Archer DB: Filamentous fungi as microbial cell factories for food use. Curr Opin Biotechnol 2000, I I(5):478-483.

2. MacKenzie DA, Jeenes DJ, Archer DB: Filamentous fungi as expression systems for heterologous proteins. In The Mycota II Edited by: Kück U. New York, Springer; 2004:289-315.

3. Conesa A, Punt PJ, van Luijk N, van den Hondel CA: The secretion pathway in filamentous fungi: a biotechnological view. Fungal Genet Biol 200I, 33(3): I55-I7I.

4. Archer DB, Peberdy JF: The molecular biology of secreted enzyme production by fungi. Crit Rev Biotechnol 1997, I7(4):273-306.

5. Gouka RJ, Punt PJ, van den Hondel CA: Efficient production of secreted proteins by Aspergillus: progress, limitations and prospects. Appl Microbiol Biotechnol 1997, 47(I): I-I I.

6. Mori K: Tripartite management of unfolded proteins in the endoplasmic reticulum. Cell 2000, 101 (5):45I-454.

7. Travers KJ, Patil CK, Wodicka L, Lockhart DJ, Weissman JS, Walter $P$ : Functional and genomic analyses reveal an essential coordination between the unfolded protein response and ERassociated degradation. Cell 2000, I 0 I(3):249-258.

8. $\mathrm{Ng} D T$, Spear ED, Walter $\mathrm{P}$ : The unfolded protein response regulates multiple aspects of secretory and membrane protein biogenesis and endoplasmic reticulum quality control. J Cell Biol 2000, 150(1):77-88.

9. Bonifacino JS, Weissman AM: Ubiquitin and the control of protein fate in the secretory and endocytic pathways. Annu Rev Cell Dev Biol 1998, 14:19-57.

10. Al-Sheikh H, Watson AJ, Lacey GA, Punt PJ, MacKenzie DA, Jeenes DJ, Pakula T, Penttila M, Alcocer MJ, Archer DB: Endoplasmic reticulum stress leads to the selective transcriptional downregulation of the glucoamylase gene in Aspergillus niger. Mol Microbiol 2004, 53(6): 1731-1742. 
II. Pakula TM, Laxell M, Huuskonen A, Uusitalo J, Saloheimo M, Penttila $M$ : The effects of drugs inhibiting protein secretion in the filamentous fungus Trichoderma reesei. Evidence for downregulation of genes that encode secreted proteins in the stressed cells. J Biol Chem 2003, 278(45):450 I I-45020.

12. Sims AH, Gent ME, Lanthaler K, Dunn-Coleman NS, Oliver SG, Robson GD: Transcriptome analysis of recombinant protein secretion by Aspergillus nidulans and the unfolded-protein response in vivo. Appl Environ Microbiol 2005, 7 I (5):2737-2747.

13. Pel HJ, de Winde JH, Archer DB, Dyer PS, Hofmann G, Schaap PJ, Turner G, de Vries RP, Albang R, Albermann K, Andersen MR, Bendtsen JD, Benen JA, van den Berg M, Breestraat S, Caddick MX, Contreras R, Cornell M, Coutinho PM, Danchin EG, Debets AJ, Dekker P, van Dijck PW, van Dijk A, Dijkhuizen L, Driessen AJ, d'Enfert C, Geysens S, Goosen C, Groot GS, de Groot PW, Guillemette T, Henrissat $B$, Herweijer M, van den Hombergh JP, van den Hondel CA, van der Heijden RT, van der Kaaij RM, Klis FM, Kools HJ, Kubicek CP, van Kuyk PA, Lauber J, Lu X, van der Maarel MJ, Meulenberg R, Menke H, Mortimer MA, Nielsen J, Oliver SG, Olsthoorn M, Pal K, van Peij NN, Ram AF, Rinas U, Roubos JA, Sagt CM, Schmoll M, Sun J, Ussery D, Varga J, Vervecken W, van de Vondervoort PJ, Wedler $\mathrm{H}$, Wosten $\mathrm{HA}$, Zeng AP, van Ooyen AJ, Visser J, Stam H: Genome sequencing and analysis of the versatile cell factory Aspergillus niger CBS 5 I3.88. Nat Biotechnol 2007, 25(2):22I-23 I

14. Elbein AD: Inhibitors of the biosynthesis and processing of $\mathbf{N}$ linked oligosaccharide chains. Annu Rev Biochem 1987 56:497-534

15. Wiebe MG, Karandikar A, Robson GD, Trinci AP, Candia JL, Trappe S, Wallis G, Rinas U, Derkx PM, Madrid SM, Sisniega H, Faus I, Montijn $R$, van den Hondel CA, Punt PJ: Production of tissue plasminogen activator (t-PA) in Aspergillus niger. Biotechnol Bioeng 2001, 76(2): I64-174.

16. Mulder HJ, Saloheimo M, Penttila M, Madrid SM: The transcription factor HACA mediates the unfolded protein response in Aspergillus niger, and up-regulates its own transcription. Mol Genet Genomics 2004, 27 I (2): I30-I40.

17. Saloheimo M, Valkonen M, Penttila M: Activation mechanisms of the HACI-mediated unfolded protein response in filamentous fungi. Mol Microbiol 2003, 47(4): I |49-I I6I.

18. MacKenzie DA, Guillemette T, Al-Sheikh H, Watson AJ, Jeenes DJ Wongwathanarat P, Dunn-Coleman NS, van Peij N, Archer DB UPR-independent dithiothreitol stress-induced genes in Aspergillus niger. Mol Genet Genomics 2005, 274(4):4I 0-4I8.

19. Rand JD, Grant CM: The thioredoxin system protects ribosomes against stress-induced aggregation. Mol Biol Cell 2006, I 7( I):387-40 I.

20. Ruegsegger U, Leber JH, Walter P: Block of HACI mRNA translation by long-range base pairing is released by cytoplasmic splicing upon induction of the unfolded protein response. Cell 200I, I07(I): I03-II4.

21. Arava Y, Wang Y, Storey JD, Liu CL, Brown PO, Herschlag D: Genome-wide analysis of mRNA translation profiles in Saccharomyces cerevisiae. Proc Natl Acad Sci U S A 2003. I 00(7):3889-3894.

22. Smith CW, Klaasmeyer JG, Edeal JB, Woods TL, Jones SJ: Effects of serum deprivation, insulin and dexamethasone on polysome percentages in C2CI 2 myoblasts and differentiating myoblasts. Tissue Cell 1999, 3 I(4):45 I-458.

23. McCarthy JE: Posttranscriptional control of gene expression in yeast. Microbiol Mol Biol Rev 1998, 62(4): I492-I553.

24. Pradet-Balade B, Boulme F, Beug H, Mullner EW, Garcia-Sanz JA: Translation control: bridging the gap between genomics and proteomics? Trends Biochem Sci 2001, 26(4):225-229.

25. Arvas M, Pakula T, Lanthaler K, Saloheimo M, Valkonen M, Suortti T, Robson G, Penttila M: Common features and interesting differences in transcriptional responses to secretion stress in the fungi Trichoderma reesei and Saccharomyces cerevisiae. BMC Genomics 2006, 7:32

26. Archer DB, Turner G: Genomics of protein secretion and hyphal growth in Aspergillus. In The Mycota XIII Edited by: Brown AJP. New York, Springer; 2006:75-96.

27. Watson AJ, Worley J, Elliott RM, Jeenes DJ, Archer DB: Cloning stress-induced genes from aspergillus niger using polymerase chain reaction-augmented subtractive hybridization. Anal Biochem 2000, 277(I): 162-165.
28. van Gemeren IA, Punt PJ, Drint-Kuyvenhoven A, Broekhuijsen MP, van't Hoog A, Beijersbergen A, Verrips CT, van den Hondel CA: The ER chaperone encoding bipA gene of black Aspergilli is induced by heat shock and unfolded proteins. Gene 1997 I 98( I-2):43-52.

29. Ngiam C, Jeenes DJ, Punt PJ, Van Den Hondel CA, Archer DB: Characterization of a foldase, protein disulfide isomerase $A$, in the protein secretory pathway of Aspergillus niger. Appl Environ Microbiol 2000, 66(2):775-782.

30. Leber JH, Bernales S, Walter P: IRE I-independent gain control of the unfolded protein response. PLoS Biol 2004, 2(8):E235.

3I. Patil CK, Li H, Walter P: Gcn4p and novel upstream activating sequences regulate targets of the unfolded protein response. PLoS Biol 2004, 2(8):E246.

32. Schroder M, Kaufman RJ: ER stress and the unfolded protein response. Mutat Res 2005, 569(I-2):29-63.

33. Kimata $Y$, Ishiwata-Kimata $Y$, Yamada S, Kohno K: Yeast unfolded protein response pathway regulates expression of genes for anti-oxidative stress and for cell surface proteins. Genes Cells 2006, I I ( I):59-69.

34. Dave A, Jeenes DJ, Mackenzie DA, Archer DB: HacA-independent induction of chaperone-encoding gene bipA in Aspergillus niger strains overproducing membrane proteins. Appl Environ Microbiol 2006, 72(I):953-955.

35. Martinez IM, Chrispeels MJ: Genomic analysis of the unfolded protein response in Arabidopsis shows its connection to important cellular processes. Plant Cell 2003, I 5(2):56 I-576.

36. Bonilla $M$, Cunningham KW: Mitogen-activated protein kinase stimulation of $\mathbf{C a ( 2 + )}$ signaling is required for survival of endoplasmic reticulum stress in yeast. Mol Biol Cell 2003, I 4( I 0):4296-4305.

37. Ellis CD, Wang F, MacDiarmid CW, Clark S, Lyons T, Eide DJ: Zinc and the Msc2 zinc transporter protein are required for endoplasmic reticulum function. I Cell Biol 2004, I 66(3):325-335.

38. Wang H, Entwistle J, Morlon E, Archer DB, Peberdy JF, Ward M, Jeenes DJ: Isolation and characterisation of a calnexin homologue, clxA, from Aspergillus niger. Mol Genet Genomics 2003, 268(5):684-69l.

39. Steel G], Fullerton DM, Tyson JR, Stirling Cl: Coordinated activation of Hsp70 chaperones. Science 2004, 303(5654):98-I0I.

40. van Huizen R, Martindale JL, Gorospe M, Holbrook NJ: P58IPK, a novel endoplasmic reticulum stress-inducible protein and potential negative regulator of elF2alpha signaling. J Biol Chem 2003, 278( I 8): I 5558-I5564.

4l. Lombrana M, Moralejo FJ, Pinto R, Martin JF: Modulation of Aspergillus awamori thaumatin secretion by modification of bipA gene expression. Appl Environ Microbiol 2004, 70(9):5|45-5|52.

42. Moralejo FJ, Watson AJ, Jeenes DJ, Archer DB, Martin JF: A defined level of protein disulfide isomerase expression is required for optimal secretion of thaumatin by Aspegillus awamori. Mol Genet Genomics 200I, 266(2):246-253.

43. Valkonen M, Ward M, Wang H, Penttila M, Saloheimo M: Improvement of foreign-protein production in Aspergillus niger var. awamori by constitutive induction of the unfolded-protein response. Appl Environ Microbiol 2003, 69(I 2):6979-6986.

44. Jeenes DJ, Pfaller R, Archer DB: Isolation and characterisation of a novel stress-inducible PDI-family gene from Aspergillus niger. Gene 1997, | 93(2):|5|-|56.

45. Wang $\mathrm{H}$, Ward M: Molecular characterization of a PDI-related gene prpA in Aspergillus niger var. awamori. Curr Genet 2000, 37(I):57-64

46. Kimura T, Hosoda Y, Sato Y, Kitamura Y, Ikeda T, Horibe T, Kikuchi $M$ : Interactions among yeast protein-disulfide isomerase proteins and endoplasmic reticulum chaperone proteins influence their activities. J Biol Chem 2005, 280(36):3 |438-3 |44|

47. Pagani M, Pilati S, Bertoli G, Valsasina B, Sitia R: The C-termina domain of yeast Erolp mediates membrane localization and is essential for function. FEBS Lett 200I, 508(I): II7-I20.

48. Helenius J, Ng DT, Marolda CL, Walter P, Valvano MA, Aebi M Translocation of lipid-linked oligosaccharides across the ER membrane requires Rft protein. Nature 2002, 41 5(6870):447-450.

49. Kuhn KM, DeRisi JL, Brown PO, Sarnow P: Global and specific translational regulation in the genomic response of Saccharomyces cerevisiae to a rapid transfer from a fermentable to 
a nonfermentable carbon source. Mol Cell Biol 200I, 2I(3):916-927.

50. Li B, Warner JR: Mutation of the Rab6 homologue of Saccharomyces cerevisiae, YPT6, inhibits both early Golgi function and ribosome biosynthesis. J Biol Chem 1996, 27I(28): I68I3-16819.

5I. Mizuta K, Warner JR: Continued functioning of the secretory pathway is essential for ribosome synthesis. Mol Cell Biol 1994, I 4(4):2493-2502.

52. van Hartingsveldt W, Mattern IE, van Zeijl CM, Pouwels $\mathrm{PH}$, van den Hondel CA: Development of a homologous transformation system for Aspergillus niger based on the pyrG gene. Mol Gen Genet 1987, 206(I):7I-75.

53. Archer DB, Jeenes DJ, MacKenzie DA, Brightwell G, Lambert N, Lowe G, Radford SE, Dobson CM: Hen egg white lysozyme expressed in, and secreted from, Aspergillus niger is correctly processed and folded. Biotechnology (N Y) 1990, 8(8):74|-745.

54. Wiebe MG, Trinci AP: Dilution rate as a determinant of mycelial morphology in continuous culture. Biotechnol Bioeng 1991, 38:75-8I.

55. Aspergillus niger genome Database . http://www.ebi.ac.uk/ genomes/eukaryota.html.

Publish with Bio Med Central and every scientist can read your work free of charge

"BioMed Central will be the most significant development for disseminating the results of biomedical research in our lifetime. "

Sir Paul Nurse, Cancer Research UK

Your research papers will be:

- available free of charge to the entire biomedical community

- peer reviewed and published immediately upon acceptance

- cited in PubMed and archived on PubMed Central

- yours - you keep the copyright

Submit your manuscript here:

http://www.biomedcentral.com/info/publishing_adv.asp
BiolMedcentral 